University of Wollongong

Research Online

Australian Institute for Innovative Materials -

Papers

Australian Institute for Innovative Materials

$1-1-2019$

\title{
Tunable Conducting Polymers: Toward Sustainable and Versatile Batteries
}

Xiaoteng Jia

University of Wollongong, xj916@uowmail.edu.au

Yu Ge

University of Wollongong,yg711@uowmail.edu.au

Liang Shao

Shaanxi University of Science and Technology, Ishao@uow.edu.au

Caiyun Wang

University of Wollongong, caiyun@uow.edu.au

Gordon G. Wallace

University of Wollongong, gwallace@uow.edu.au

Follow this and additional works at: https://ro.uow.edu.au/aiimpapers

Part of the Engineering Commons, and the Physical Sciences and Mathematics Commons

Research Online is the open access institutional repository for the University of Wollongong. For further information contact the UOW Library: research-pubs@uow.edu.au 


\title{
Tunable Conducting Polymers: Toward Sustainable and Versatile Batteries
}

\author{
Abstract \\ Rapid growth of smart electronics and implantable medical devices markets has driven the development \\ of next-generation sustainable, flexible, or implantable batteries. Conducting polymers with unique \\ mechanical and electronic properties offer new possibilities and have attracted great attention. In this \\ review, we discuss approaches used to tune conducting polymers at the molecular level for designated \\ properties and applications such as improved electrochemical performance, and we discuss approaches \\ used to tune conducting polymers at the molecular level to enhance selected properties for applications \\ such as lithium/sodium ion batteries, biodegradable electrodes or enhanced solution processability for \\ advanced manufacture of such structures. We provide here insights into the molecular structure- \\ electrochemical performance relationships. Finally, we present perspectives on the further development \\ of conducting polymer materials for these novel batteries. \\ Disciplines \\ Engineering | Physical Sciences and Mathematics

\section{Publication Details} \\ Jia, X., Ge, Y., Shao, L., Wang, C. \& Wallace, G. G. (2019). Tunable Conducting Polymers: Toward \\ Sustainable and Versatile Batteries. ACS Sustainable Chemistry and Engineering, 7 14321-14340.
}

This journal article is available at Research Online: https://ro.uow.edu.au/aiimpapers/3806 


\title{
Tunable Conducting Polymers: Toward Sustainable and Versatile Batteries
}

\author{
Xiaoteng $\mathrm{Jia}^{1 \#}$, Yu Ge${ }^{1}$, Liang $\mathrm{Shao}^{2}$, Caiyun Wang ${ }^{1 *}$, Gordon G. Wallace ${ }^{1 *}$
}

1. ARC Centre of Excellence for Electromaterials Science, Intelligent Polymer Research Institute, AIIM Facility, University of Wollongong, NSW 2522, Australia

2. Shaanxi Key Laboratory of Chemical Additives for Industry, Shaanxi University of Science and Technology, Xi'an 710021, China

\# Current address: Department of Chemical Engineering and Materials Science, University of California, Irvine, Irvine, CA 92697, USA.

E-mails: caiyun@uow.edu.au; gwallace@uow.edu.au

\begin{abstract}
Rapid growth of smart electronics and implantable medical devices markets have driven the development of next generation sustainable, flexible, or implantable batteries. Conducting polymers with unique mechanical and electronic properties offer new possibilities and have attracted great attention. In this review, we discuss the main approaches used to tune conducting polymers at molecular level for designated properties and applications such as improved electrochemical performance, we discuss approaches used to tune conducting polymers at the molecular level to enhance selected properties for applications such as lithium/sodium ion batteries, biodegradable electrodes or enhanced solution processability for advanced manufacture of such structures. We provide here insights into the molecular structure-electrochemical performance relationships. At last we present perspectives on the further development of conducting polymer materials for these novel batteries.
\end{abstract}

Keywords: Conducting polymers, batteries, electrodes, doping, structure-property relationships.

\section{Introduction}

Energy storage is the cornerstone of a sustainable energy supply system. It bridges the gap between the intermittent energy generated from renewable power sources such as solar, wind, and high energy on demand. Portable electronic devices such as laptops, smartphones, 
integrated circuit smart cards and wearable sensors have become an integral part of daily life. ${ }^{1,}$ ${ }^{2}$ The performance of these devices is critically dependent on the energy supply system, which is currently dominated by lithium and lithium-ion batteries (LIBs); owing to their high energy density, long service life and wide operating temperature in comparison to other energy storage systems. ${ }^{3,4}$ Inorganic materials (mainly transition metal compounds) have been widely used as cathode materials since the commercialisation of LIBs in 1991 by Sony. ${ }^{5}$ Great concern has arisen with the large-scale use of transition metal based electrode materials: sustainability of resources, environmental pollution and large energy consumption in both synthesis and recycling. The use of these non-renewable materials challenges the sustainable devolvement of energy storage devices. ${ }^{6-9}$ Organic electrodes materials can be considered as sustainable materials, as they may be extracted directly or eventually synthesized from biomass and recycled through carbon dioxide cycling. ${ }^{10}$ Ideally, there would no additional $\mathrm{CO}_{2}$ footprint in the whole process, and much less energy is consumed during chemosynthesis and thermal recycling. These organic electrodes may circumvent the drawbacks of resources depletion and environmental issues from using metal-based compounds electrodes. ${ }^{11,12}$

Currently there has also been a surge in demand for flexible and wearable electronics that can monitor, sense and communicate, ${ }^{13,14}$ and this puts extra demands on power sources possessing similar configurations and functionalities. These ambitious requirements have triggered rapid developments in versatile electrode materials with flexibility, printability and new functionality. For some applications, cytocompatible and biodegradable structures would be ideal in providing transient functions to enhance biological processes, such as wound healing, bone revival or muscle repair. ${ }^{15,16}$ Compared to the commonly used inorganic intercalation materials, electroactive organic materials with inherent redox properties are promising candidates. Organic electrode materials mainly include conducting polymers (CPs), organosulfur compounds, organic free radical compounds, and organic carbonyl compounds. ${ }^{17,} 18$ Amongst them, CPs are promising materials for sustainable and versatile batteries because of their unique electronic properties of metals or metal oxides and mechanical properties of polymers. ${ }^{19}$ Their high electrochemical performance in combination with unique features of flexibility, processability and structural diversity provide them great perspective in a variety of battery systems, such as lithium ion ${ }^{20}$, sodium ion $^{21}$, metal air $^{22}$, lithium-sulfur ${ }^{23}$ and all-polymer batteries $^{24}$. 
CPs are characterized by a polymer backbone consisting of alternating single and double bonds. Their overlapping p-orbitals create a system of delocalised $\pi$-electrons, leading to interesting and useful optical and electronic properties. ${ }^{25}$ The most fascinating CPs for battery applications are polyheterocycles, such as polypyrrole (PPy), polyaniline (PANI), polythiophene (PTh), poly(3,4-ethylenedioxythiophene) (PEDOT) and their derivatives (molecular structures shown below). ${ }^{26}$ They typically exhibit an electrical conductivity in the range of 0.01 to $500 \mathrm{~S} \mathrm{~cm}^{-1} .{ }^{27}$ The use of CPs in lithium batteries (i.e. PANI as cathode material) can be traced back to the late $1980 \mathrm{~s} .{ }^{28,29}$ Research in this area is continuing to grow with the objective to tune their intrinsic properties. The great structural diversity and synthetic tailorability of CPs enable tuning of electrochemical properties (i.e., redox potential, doping level, number of electrons involved) and/or introducing of new functionalities (i.e., solution processability, biodegradability)..$^{30,31}$

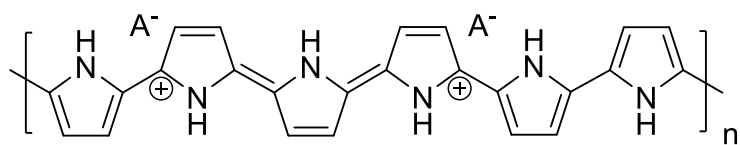

Polypyrrole (PPy)

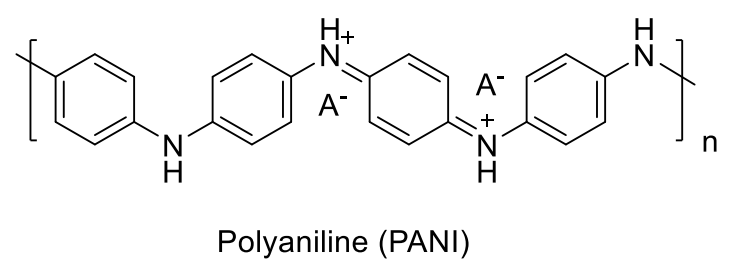

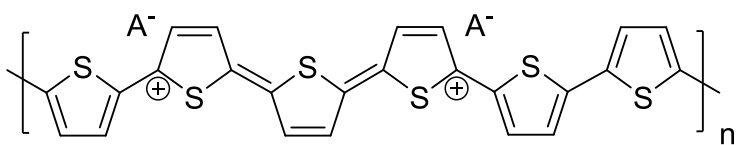

Polypthiophene (PTh)

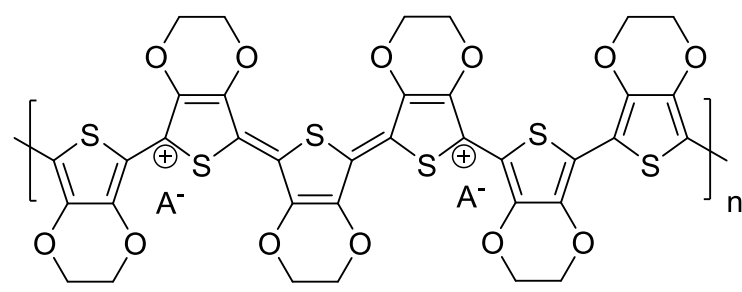

Poly(3,4-ethylenedioxythiophene) (PEDOT)

A number of excellent reviews have appeared that focus on the deployment of CPs in battery technology. ${ }^{32-35}$ However, no dedicated review about tuning CPs for targeted properties at molecular level is available, neither for the emerging type of implantable, spinnable and printable batteries. Here we provide a comprehensive review of CPs for the next-generation of sustainable and versatile batteries. It starts with a general introduction of the working principles and reaction mechanisms of well-established Li-ion batteries and relatively new Na-ion batteries. Modifying CPs with redox active groups to improve the electrochemical properties are critically discussed. Then their applications in new emerging cytocompatible/biodegradable batteries are discussed along with the introduction of additional functionalities. We also present the development of spinnable and printable CPs electrodes for batteries with unconventional 
configurations through engineering their solution processability. Lastly, we provide perspectives for future development of CPs electrodes.

\section{Conducting Polymers in Lithium Ion and Sodium Ion Batteries}

\section{Operation Principle}

The electroactivity and conductivity of CPs facilitate their applications in rechargeable batteries. An extended $\pi$-conjugation endows CPs with metal-like or semiconductor properties. They are only conducting when doped, and the electrical conductivity depends on the extent of doping. ${ }^{36,37}$ Doping is the process of reducing (n-doping) or oxidizing (p-doping) a neutral polymer through incorporation of a counter cation or anion (dopant), as illustrated in the following reactions where $\mathrm{C}^{+}$and $\mathrm{A}^{-}$represents the doping counterions. ${ }^{38}$

$$
\begin{aligned}
& \text { n-Doping }\left[\mathrm{CP}^{0}\right]_{\mathrm{n}}+\mathrm{n} \mathrm{e}^{-}+\mathrm{n} \mathrm{C}^{+} \rightleftharpoons\left[\mathrm{CP}^{-}\right]\left[\mathrm{C}^{+}\right]_{\mathrm{n}} \\
& \text { p-Doping }\left[\mathrm{CP}^{0}\right]_{\mathrm{n}}+\mathrm{n} \mathrm{A}^{-} \rightleftharpoons\left[\mathrm{CP}^{+}\right]\left[\mathrm{A}^{-}\right]_{\mathrm{n}}+\mathrm{ne}^{-}
\end{aligned}
$$

This process introduces charge carriers in the form of charged polarons (radical ions) or bipolarons (dications or dianions) into the polymer. During the doping/dedoping process, counterions are expelled from or migrate into the polymer backbone to maintain electroneutrality. ${ }^{39}$

The fact that CPs can be charged/discharged is attributed to the doping/dedoping process accompanied with the mobility of anions or cations. CPs are commonly used as cathodes owing to their electrochemical stability in p-doped states. In a Li-ion battery, a p-type CP serves as the cathode and a carbon material functions as the anode (Figure 1). Dopants $\left(\mathrm{A}^{-}\right)$are transferred from cathode to electrolyte, while $\mathrm{Li}$ ions are transferred from anode to electrolyte. Electrolyte should contain sufficient $\mathrm{Li}^{+}$and $\mathrm{A}^{-}$to ensure conductivity and availability of ions. The discharge process involves the uptake of electrons and release of dopant anions for $\mathrm{CP}$, while the anode gives up electrons and releases Li ions. During the charging process, Li cations are reduced and stored in the carbon material, while the $\mathrm{CP}$ is simultaneously oxidized by losing electrons. ${ }^{40}$ 


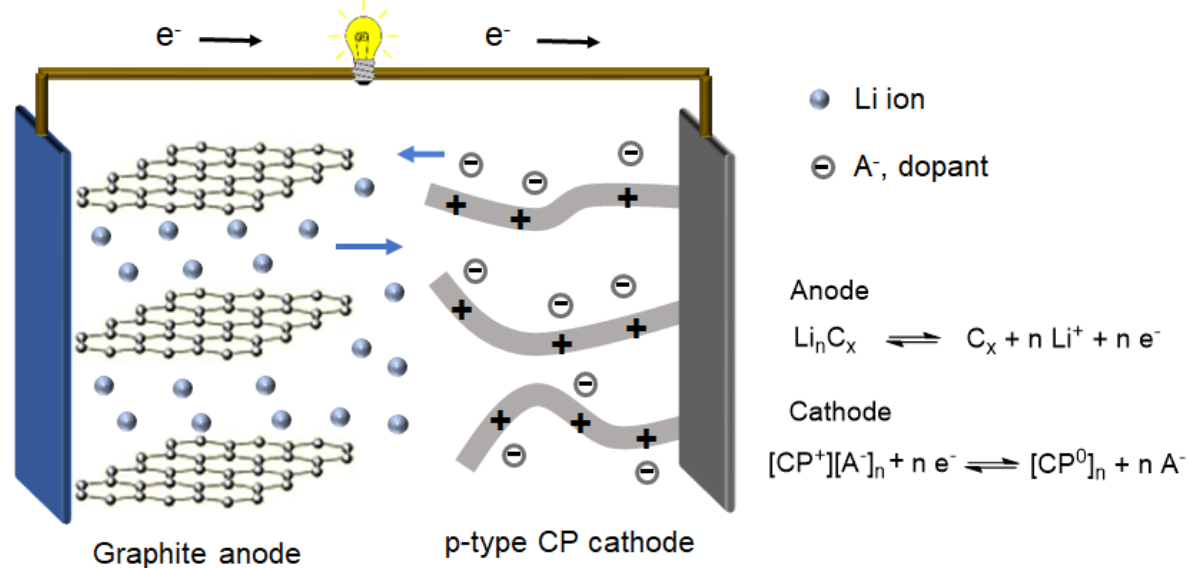

Figure 1 General redox chemistries and a schematic working principle of a Li-ion battery using a p-type $\mathrm{CP}$ cathode and a carbon-based anode during discharge; $\mathrm{A}^{-}$represents the doping ions.

Sodium-ion batteries (SIBs) are emerging as an alternative to LIBs due to the abundance of $\mathrm{Na}$ in the earth's crust. ${ }^{41}$ Since $\mathrm{Li}$ and Na share common properties as alkali metals, the working principle of SIBs is similar to that of LIBs. ${ }^{42}$ However, research on SIBs is still in its infancy with the search for active materials with sufficiently large interstitial spacing to host $\mathrm{Na}$ ion. The Na ion has an ionic radius $0.3 \AA$ larger than Li ion. ${ }^{43}$ In terms of CPs, their "soft" nature allows the intercalation of ions in large size, thus they are suitable materials for SIBs as well. ${ }^{44}$

\section{Modification of Conducting Polymers}

The specific capacity offered from CPs is attributed to their attainable doping levels. ${ }^{45} \mathrm{CPs}$ typically possess a doping level of 0.3-0.5 (i.e., 0.5 holes per monomer ring in PANI, 0.33 in PPy and 0.25 in PTh), ${ }^{46}$ affording a capacity in the range of $82-147 \mathrm{mAh} \mathrm{g}^{-1}{ }^{32}$ Higher doping levels may lead to irreversible destruction of CPs. ${ }^{47} \mathrm{CPs}$ suffer from another critical issue of sloping voltage profile when discharged, because the voltage of CPs strongly depends on the doping level and it changes upon charging/discharging. ${ }^{48}$ These drawbacks may be overcomed by using organic synthetic tools such as embedding redox active groups at molecular level. It can be achieved through either covalently linked to polymer backbone as pendants (forming conducting redox polymers) or doped into the polymer matrix as a counterion. ${ }^{49}$ Organic redox molecules that can be incorporated into the CPs matrix mainly include metal complexes, carbonyls, radical compounds, and organosulfur compounds, which contain atoms with lone pair electrons such as $\mathrm{N}, \mathrm{S}$, and O. ${ }^{50,51}$ This design facilitates the insertion/extraction of $\mathrm{Li} / \mathrm{Na}$ ions in addition to the doping/dedoping process of CPs. ${ }^{52,53}$ Thus, they can harness the properties of both the conjugated polymeric backbone (providing conducting path and charge 
capacity) and redox groups (introducing additional charge capacity), thereby enhancing performance. It should be pointed out that the integration of organic redox molecules interrupts the $\pi$-conjugation of CPs and limits the ability to stabilize the charge carrier. Thus, the doping level of CPs is limited resulting in lower electronic conductivity..

\section{Polypyrrole (PPy)}

PPy consists of repeating units of pyrrole that are primarily connected at the $\alpha$-positions. The additional functionality can be obtained by substitution on the available $\beta$-carbon or nitrogen. In 2007, Park et al. covalently anchored ferrocene groups on the nitrogen of pyrrole unit, yielding a copolymer with 50\% functionalized unit (Figure 2a). ${ }^{54}$ This redox pair presented its own charge storage behavior displaying flat charge/discharge plateau in contrast to the sloping one for PPy. The formed pyrrole/[(ferrocene) amidopropyl]pyrrole copolymer (PPy/ferrocene) displayed a specific capacity of $65 \mathrm{mAh} \mathrm{g}^{-1}$, higher than that $20 \mathrm{mAh} \mathrm{g}^{-1}$ for unmodified PPy (Figure 2b). Redox-active molecule viologen can be covalently bound with the pyrrole unit via an alkyl linker at the nitrogen position $\left(\mathrm{PPy}-\mathrm{V}^{2+}-\mathrm{Me}\right.$, Figure $\left.2 \mathrm{c}\right) .{ }^{55}$ With three one-electron redox states, viologens exhibited rapid and reversible electron transfer at lower potential. This material exhibited a capacity of $55 \mathrm{mAh} \mathrm{g}^{-1}$ when coupled with Li foil anode, higher than 30 $\mathrm{mAh} \mathrm{g}^{-1}$ from PPy incorporated with 1,1'-bis(2,4-benzenedisulfonate)-4,4'-bipyridinum dibromide (VTS) (PPy[VTS]) (Figure 2d). As an organic nitroxyl radical group, 2,2,6,6tetramethylpiperidine-N-oxyl (TEMPO) reveals excellent electrochemical stability and fast redox kinetics. ${ }^{56}$ Recently, it has been introduced as pendant substituents at the $\mathrm{N}$ position of pyrrole unit. ${ }^{57}$ A significantly improved discharge capacity of $115 \mathrm{mAh} \mathrm{g}^{-1}$ was achieved, compared with only $16.5 \mathrm{mAh} \mathrm{g}^{-1}$ for pure PPy. 
a

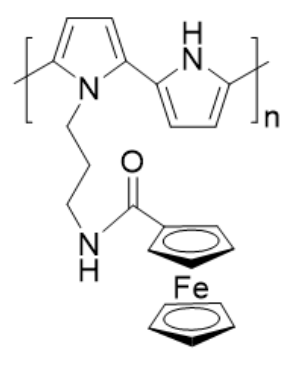

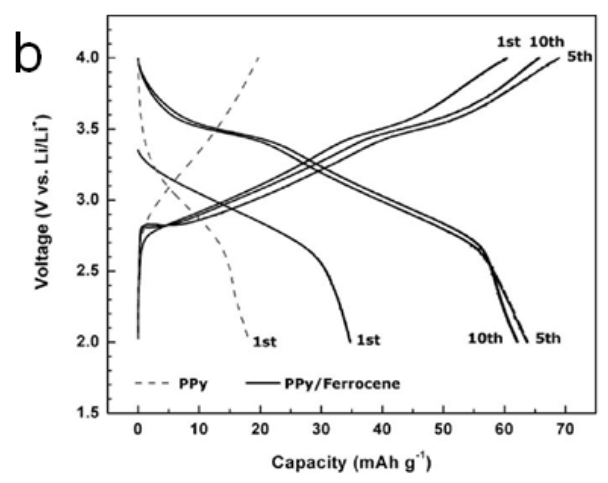
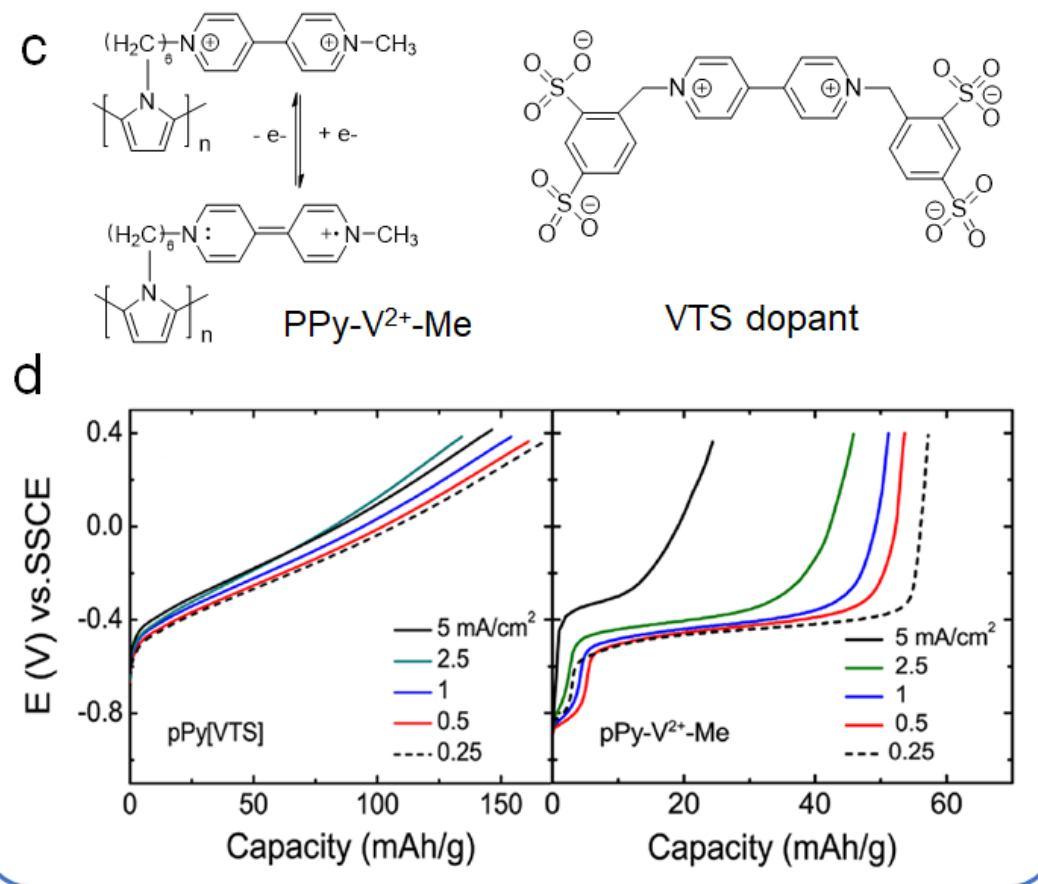

Figure 2 (a) Chemical structure of PPy/ferrocene; (b) Charge-discharge curves of PPy and $\mathrm{PPy} /$ ferrocene polymer cathode in a LIB at C/5; (Reproduced with permission from ref. 54. Copyright 2007, WILEY-VCH Verlag GmbH \& Co. KGaA, Weinheim). (c) Chemical structures of PPy with viologen as pendant substituent and PPy with [VTS] as dopant; (d) Discharge curves of PPy[VTS] and PPy- $\mathrm{V}^{2+}-\mathrm{Me}$; (Reproduced with permission from ref. 55. Copyright 2013, American Chemical Society).

Substitution on nitrogen is relatively easy to achieve but has detrimental effects on the conductivity due to the steric hindrance from the twisted pyrrole units. Using $\beta$-substitution is a promising option to achieve functionalization without disrupting the PPy backbone. Sjödin's group has developed a series of CRPs based on PPy with hydroquinone pendant groups that are attached to the $\beta$-carbon via different linkers. ${ }^{58,59}$ Quinone is a carbonyl compound with low molar mass molecular that undergoes a reversible two-electron exchange process at a 
relatively high potential $\left(\sim 2.6 \mathrm{~V} v s . \mathrm{Li} / \mathrm{Li}^{+}\right)$, affording a theoretical specific capacity of 495 $\mathrm{mAh} \mathrm{g}^{-1} \cdot{ }^{60}$ Organosulfides are another type of redox groups used to modify pyrrole unit at the $\beta$-position. They contains disulfide bonds providing the charge capacity through a S-S electrodimerization/scission redox reaction. ${ }^{12}$ An intramolecular cyclic disulfide-containing poly(4,6dihydro-1H-[1,2]dithiino[4,5-c]pyrrole) showed less over-oxidation, good redox properties, and a high discharge capacity of $398 \mathrm{mAh} \mathrm{g}^{-1}$ as a cathode material in lithium secondary batteries. $^{61}$

In addition to covalently linking redox-active pendants into CPs backbones, another approach is to construct a Na host by grafting ionisable organic sodium salts on the polymer backbone. ${ }^{62}$ $\mathrm{Na}$ ions can be inserted/extracted from the polymer chain during the charge/discharge processes. The operational mechanism is insertion/extraction instead of conventional doping/de-doping. For example, Yang et al. developed a self-doped PPy by grafting nitrogen atom with ionizable sodium sulfonate. ${ }^{63}$ Due to the immobile self-doping of organic anions, this material can act as a Na-host for reversible $\mathrm{Na}$ insertion-extraction reaction as evidenced by the distinct peaks in cyclic voltammograms $(\mathrm{CV})$. The resultant poly(pyrrole-co-(sodium3-(pyrrolyl) propanesulphonate)) copolymer (PPy-PS) was effective in storing $\mathrm{Na}$ ions and showed a capacity of $85 \mathrm{~mA} \mathrm{~g}^{-1}$, and it was steady over 100 cycles.

\section{Polyaniline (PANI)}

In 1999, Hass et al. immobilized quinone groups into the benzoid of PANI backbone to improve conductivity and decrease solubility. ${ }^{64}$ Quinone groups were first introduced to aniline monomer by the electropolymerization of naphthalene derivatives bearing - $\mathrm{OH}$ or $-\mathrm{NH}_{2}$ groups as substituents. For example, 5-amino-1,4-naphthoquinone (ANQ) monomers are typically synthesised by nitrating 1,4-naphthoquinone in a mixture of concentrated $\mathrm{H}_{2} \mathrm{SO}_{4}$ and $\mathrm{NaNO}_{3}$ at $5{ }^{\circ} \mathrm{C}$, followed by the reduction into $-\mathrm{NH}_{2}$ group by $\mathrm{SnCl}_{2} \cdot{ }^{65}$ Polymers with a PANI-like structure are then chemically or electrochemically polymerized from the corresponding monomers. The resultant poly(5-amino-1,4-naphthoquinone) (PANQ) showed a capacity of

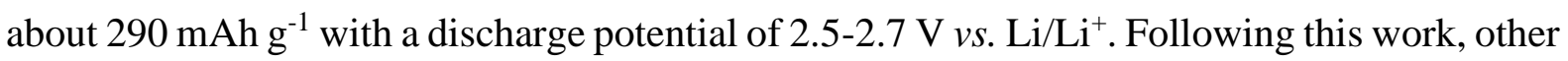
types of CRPs with quinone connected to N-H group were developed. ${ }^{66}$ A good capacity retention of $160 \mathrm{mAh} \mathrm{g}^{-1}$ over 200 cycles was achieved for poly(1,5-diaminoanthraquinone) (PDAQ). ${ }^{67}$ Recently, Vlad et al. reported on the synthesis of poly(2,5-dihydroxyaniline) (PDHA) by chemical demethylation with redox quinone as part of the polymer backbone (Figure 3a). ${ }^{68}$ The intramolecular cross-hybridization of quinone redox and PANI moieties 
lead to a subtle interplay between the redox stability and lithiation capacity, showing a theoretical capacity of $443 \mathrm{~mA} \mathrm{~h} \mathrm{~g}^{-1}$. PDHA displayed a pair of redox peaks centred at $2.3 \mathrm{~V}$ and $2.6 \mathrm{~V}$ that could be assigned to a two-electron process for quinone groups (Figure $3 \mathrm{~b}$ ). The assembled cell coupled with lithium displayed an open circuit potential in a range of 2.8-3.2 V (vs. $\mathrm{Li} / \mathrm{Li}^{+}$) (Figure 3c), and an initial capacity of $180 \mathrm{mAh} \mathrm{g}^{-1}$ in an organic carbonate-based electrolyte.

Organosulfur polymers with disulfide bond in the main chain generally show a redox process accompanied by depolymerisation and structural changes of main chains. ${ }^{48}$ The recombination efficiency of S-S bonds is very low leading to a poor reversibility. ${ }^{69}$ It can be improved when the S-S bond is installed in the side chain. The first side chain type organosulfur polymer poly (2,2'-dithiodianiline) (PDTDA) was introduced as a cathode material in lithium batteries in $1997 .{ }^{70}$ It had one S-S bond interconnected between two moieties of anilines. A capacity of $270 \mathrm{mAh} \mathrm{g}^{-1}$ coupled with a flat voltage of $2.5 \mathrm{~V} v$ s. $\mathrm{Li} / \mathrm{Li}^{+}$was achieved using a gel polymer electrolyte. This PANI-based CRP showed a conductivity in the level of $10^{-2} \mathrm{~S} \mathrm{~cm}^{-1}$, two orders of magnitude lower than that $0.1-5 \mathrm{~S} \mathrm{~cm}^{-1}$ for PANI; ${ }^{71}, 72$ as a result of the steric hindrance induced by the sulphide substitution for reduced structural order of polymers. Notably, a conducting PANI derivative containing -O-S-S-O- links, exhibited a high energy density (460 $\left.\mathrm{mWh} \mathrm{g}^{-1}\right){ }^{73}$ In particular, the theoretical capacity of poly( $\alpha, \alpha^{\prime}$-dithio-3-amino-o-xylene) (PDTAn) is $370 \mathrm{mAh} \mathrm{g}^{-1}$ (assuming a doping level of 0.5 for PANI), higher than PDTDA thanks to the high sulfide density in the in-chain-disulfide design. ${ }^{74}$

Other redox groups such as 2,2,6,6-tetramethylpiperidine-N-oxyl ${ }^{75}$ and ferrocene unit ${ }^{76}$ have also been introduced into the PANI backbone. A redox-active $\mathrm{N}$-methylthionine unit was copolymerized with aniline monomer, yielding a copolymer (PANMTh) with phenothiazine ring in the main chain resulting in an improvement of electroactivity in high $\mathrm{pH}$ electrolyte. ${ }^{77}$ When assembled in an aqueous Zn-polymer secondary battery, it delivered a high specific capacity of $146.3 \mathrm{mAh} \mathrm{g}^{-1}$ and retained $\sim 99.4 \%$ of the capacity over 150 consecutive cycles. Similar as Park's PPy work in $2007,{ }^{54}$ a copolymer ferrocene-substituted aniline was synthesized. ${ }^{76}$ It demonstrated an improved discharge plateau over the potential range of 3.0$4.0 \mathrm{~V}\left(v s \mathrm{Li}^{+} / \mathrm{Li}\right)$, and a good cycling stability with an $8 \%$ loss over 30 cycles.

Na-rich PANI cathode, poly(aniline-co-aminobenzenesulfonic sodium) (PANS), was recently developed by grafting electron withdrawing $-\mathrm{SO}_{3} \mathrm{Na}$ groups onto PANI chains and investigated for SIB application (Figure 3d). ${ }^{78}$ Due to the immobile dopant and effective activation of 
sulfonate group, PANS cathode delivered a reversible capacity of $133 \mathrm{mAh} \mathrm{g}^{-1}$ with an excellent capacity retention rate of $97 \%$ after 200 cycles (Figure 3e,f). It also showed an impressive rate capability possibly due to the flexibility of polymer framework affording less resistance to insertion/extraction of $\mathrm{Na}$ ions. Electron withdrawing o-nitroaniline had also been grafted onto PANI chains. ${ }^{79}, 80$ The aniline-nitroaniline copolymer P(AN-NA) delivered a capacity of $180 \mathrm{mAh} \mathrm{g}^{-1}$ at an average potential of $3.2 \mathrm{~V} v s . \mathrm{Na} / \mathrm{Na}^{+}$and a reversible capacity of $173 \mathrm{mAh} \mathrm{g}^{-1}$ after 50 cycles.

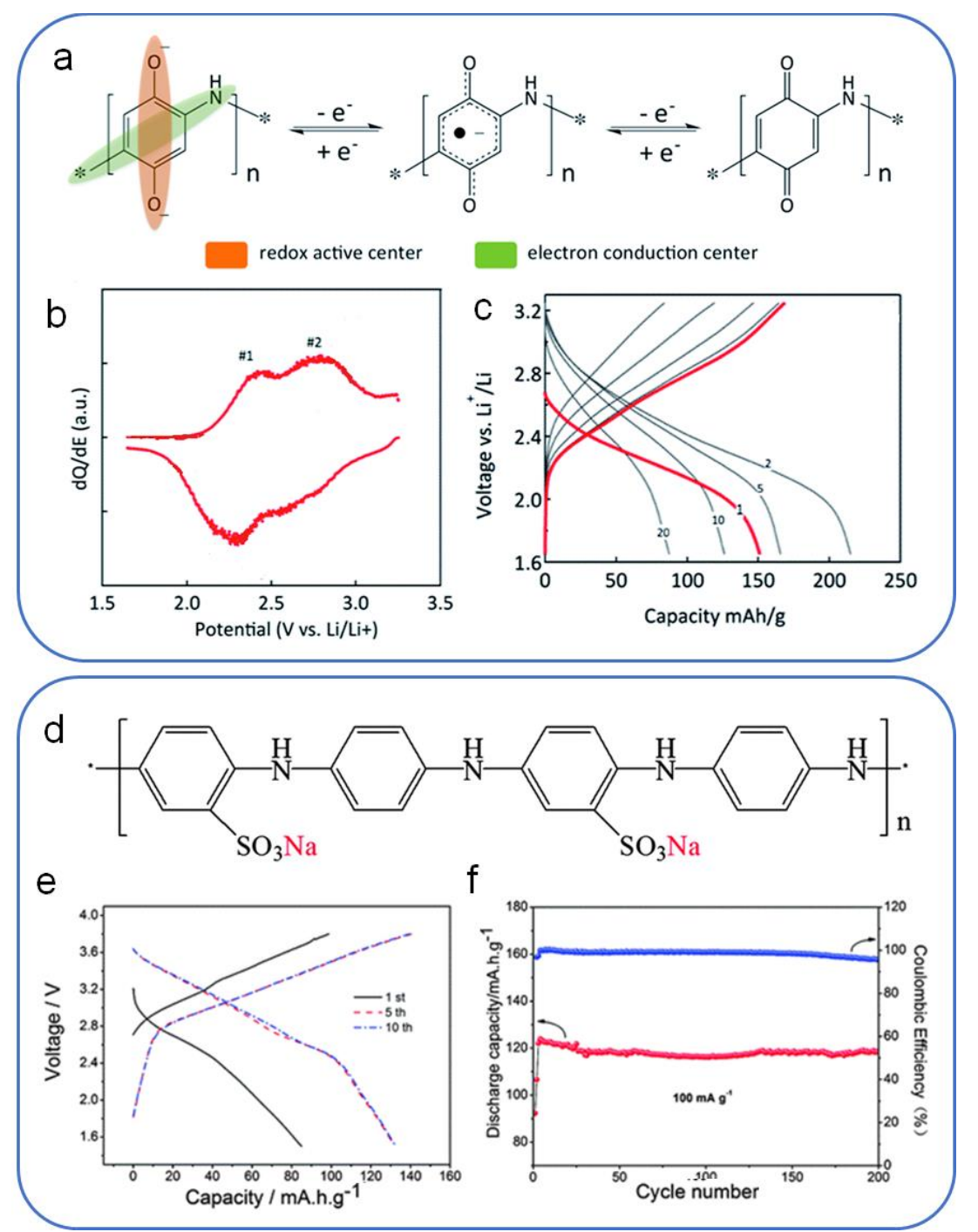

Figure 3 (a) Molecular formula and redox reactions of poly(2,5-dihydroxyaniline) (PDHA); (b) Differential capacity plots for PDHA, two characteristic redox peaks are related to a twoelectron transfer for quinone groups; (c) Charge-discharge profiles (at C/10 rate) for PDHA; (Reproduced with permission from ref. 68. Copyright 2015, Royal Society of Chemistry). (d) The molecular structure of PANS; (e) Charge-discharge profiles during the first ten cycles at 
$50 \mathrm{~mA} \mathrm{~g}^{-1}$; (f) Cycling performance at $100 \mathrm{~mA} \mathrm{~g}^{-1}$. (Reproduced with permission from ref. 78 . Copyright 2015, Royal Society of Chemistry).

\section{Polythiophene (PTh)}

PTh and its derivatives have attracted attention in the field of energy storage due to their stable n-doping state by using side chain functionalization. ${ }^{81}$ Like PPy, PTh can also be modified via grafting functional groups to $\beta$-carbon or sulfur atom. A stable anode $\beta$-substituted poly(phenylene-thiophene) material demonstrated a significant enhancement in the $n$-doping capacity. ${ }^{82}$ Introducing fluorine at the phenyl ring further improved the capacity and redox stability of poly(phenylene-thiophene). ${ }^{83,} 84$ The electron withdrawing effect from the substituent can stabilize the charge accumulation on the backbone, thereby increasing the doping level and stability. A series of fluorine-substituted poly(phenylene-thiophene) with fluorine atoms at various positions of phenyl ring have been designed and synthesized. ${ }^{85}$ The electrochemical property of these functionalized CPs was influenced by the steric and electronic character of pendant groups. A maximum doping level of 0.45 holes per repeat unit was achieved coupled with a cycling efficiency of up to $99.58 \%$ attained per cycle. ${ }^{83}$ The PTh incorporated with a high electron affinity group oxadiazole was endowed with a stable ndoping level of 1.35 per repeat unit in an ionic liquid electrolyte. ${ }^{86}$

Recently, Liang et al. reported a conjugated redox polymer poly $\{[\mathrm{N}, \mathrm{N}$ '-bis(2-octyldodecyl)1,4,5,8-naphthalenedicarboximide-2,6-diyl]-alt-5,5'-(2,2' bithiophene)\} (P(NDI2OD-T2)) featuring stable and reversible n-doping with an enhanced electronic conductivity (Figure 4a). ${ }^{87}$ This polymer was constructed by bridging a linear $\pi$-conjugated bithiophene unit, which provided an electron-transport pathway within a naphthalene dicarboximide (NDI) unit. Every NDI unit contained four carbonyl groups, two of which were expected to be reversibly reduced via a two-step two-lithium addition reaction corresponding to an $n$-doping level of $\sim 2.0$. Being a Li storage material, P(NDI2OD-T2) delivered a specific capacity of $54.2 \mathrm{mAh} \mathrm{g}^{-1}$, nearly $100 \%$ of its theoretical capacity (given a 2-electron redox reaction) (Figure 4b). It delivered $95 \%$ of its theoretical capacity at a high rate of $100 \mathrm{C}$ along with a $96 \%$ capacity retention rate over 3,000 cycles (Figure 4c). This ultrafast electrode kinetics was ascribed to high electronic conductivity at the heavily n-doped state. Another n-doping conjugated redox polymer with PTh backbone and diethyl terephthalate pendant groups was synthesized and applied as anode material in a LIB. ${ }^{88}$ The conductivity of this polymer was not compromised by the presence of pendant groups, thus allowed for fast charge transport resulting in excellent rate capability. 
Conjugated radical polymers have captured great attention for high power and fast redox kinetics. ${ }^{89}$ However, they delivered very low specific capacity compared with their theoretical capacity. ${ }^{90}$ Lutkenhaus et al. recently synthesized a series of $\beta$-substituted PTh bearing TEMPO radicals with varying alkyl spacer groups (Figure 4d). ${ }^{91}$ A specific capacity of $68 \mathrm{mAh} \mathrm{g}^{-1}$ was delivered with tetramethyl alkyl groups, corresponding to $38.2 \%$ of its theoretical capacity. By monitoring the open circuit potential decay via in situ spectroelectrochemistry, a rapid dedoping process was verified for the PTh backbone, which was caused by internal electron transfer from the nitroxide group to PTh backbone (Figure 4e,f). This internal electron transfer interfered with the stabilization of polymer in the fully oxidized state.

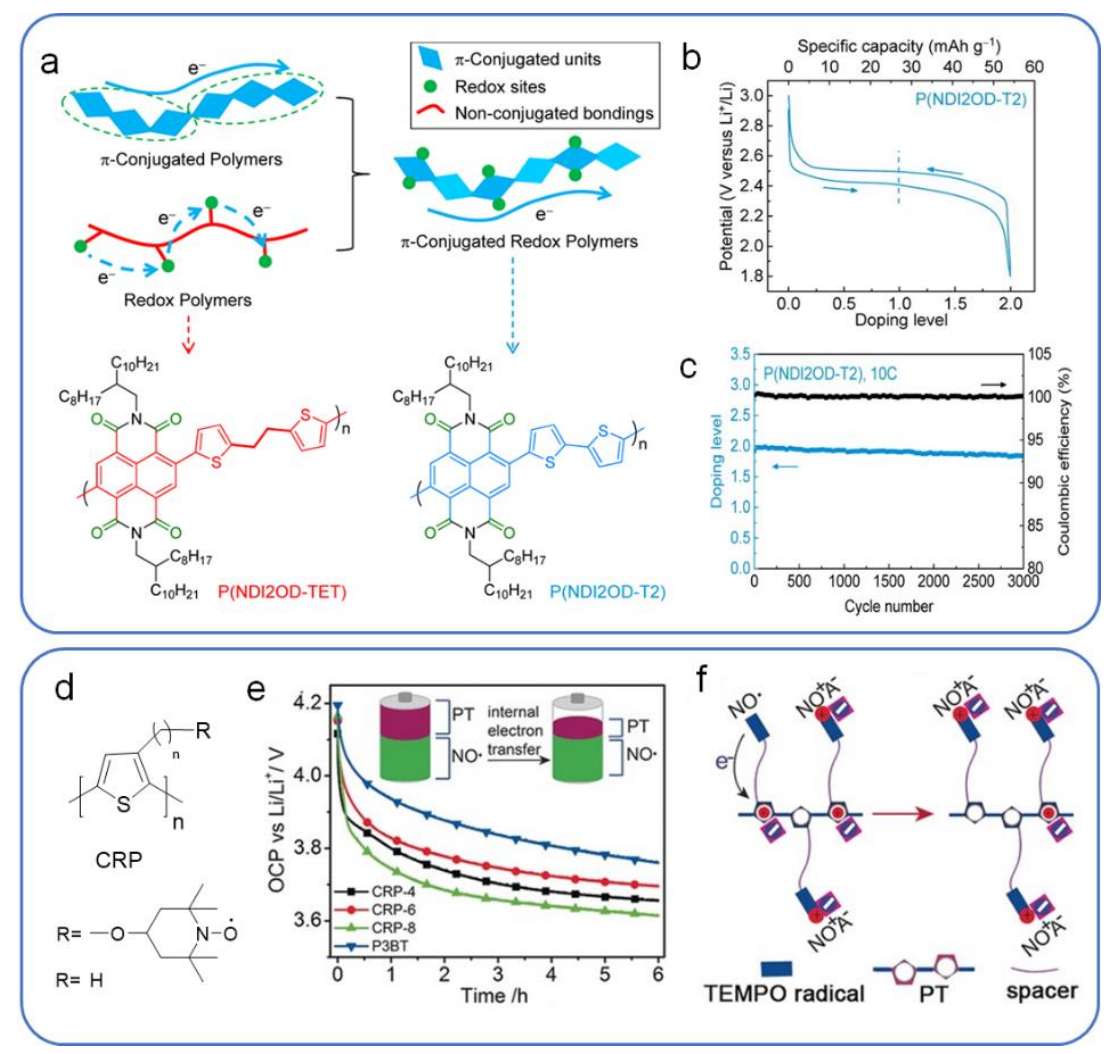

Figure 4 (a) Graphical illustration and molecular structure of non-conjugated P(NDI2OD-TET) and $\pi$-conjugated $\mathrm{P}(\mathrm{NDI} 2 \mathrm{OD}-\mathrm{T} 2)$; (b) Potential profile of $\mathrm{P}(\mathrm{NDI} 2 \mathrm{OD}-\mathrm{T} 2)$ during $\mathrm{n}$ doping/dedoping at $1 \mathrm{C}$; (c) Reversibility of $\mathrm{P}(\mathrm{NDI} 2 \mathrm{OD}-\mathrm{T} 2)$ during repeated $\mathrm{n}$ doping/dedoping at 10C; (Reproduced with permission from ref. 87, Copyright 2015, American Chemical Society). (d) Chemical structure of PTh conjugated radical polymers with alkyl spacers; (e) Open-circuit potential monitoring for $6 \mathrm{~h}$ with an inset illustrating the changes of CRPs; (f) Illustration of an internal electron-transfer process occurring for CRP; (Reproduced with permission from ref. 91, Copyright 2017, WILEY-VCH Verlag GmbH \& Co. KGaA, Weinheim). 
Vulcanization is a facile and low-cost method to stabilize polymeric sulfur against depolymerization. Recently, copolymers of PTh and sulfur prepared by the inverse vulcanization have demonstrated excellent electrochemical performance in Li-S batteries. ${ }^{92,93}$ The poly(3-hexylthiophene-2,5-diyl) (P3HT) and S8 copolymer (S-P3HT) exhibits an enhanced battery performance with respect to the cycling performance at $0.5 \mathrm{C}\left(799 \mathrm{mAh} \mathrm{g}^{-1}\right.$ after 100 cycles for S-P3HTcopolymer versus only $544 \mathrm{mAh} \mathrm{g}^{-1}$ for the simple mixture) and the C-rate performance. ${ }^{94}$ This is attributed to the attractive interaction between polysulfides and P3HT hindering the dissolution of polysulfides and the charge transfer due to the homogeneous incorporation of P3HT into sulfur by covalently linking sulfur and P3HT.

In this section, we have summarised the developments of CPs with redox-active groups and ionizable organic anions as electrode materials in secondary batteries. CRPs afford an improved battery performance in terms of higher plateau voltage, higher capacity and stable cyclic capability compared with pristine CPs. Further work should pay attention to the matching of redox potentials between redox groups and conjugated backbone for achieving a stable CRP. To provide an overview of this field, structures of conducting redox polymers and their performance are outlined in Table 1 for a comprehensive comparison.

Table 1. Overview of conducting redox polymers in secondary batteries .

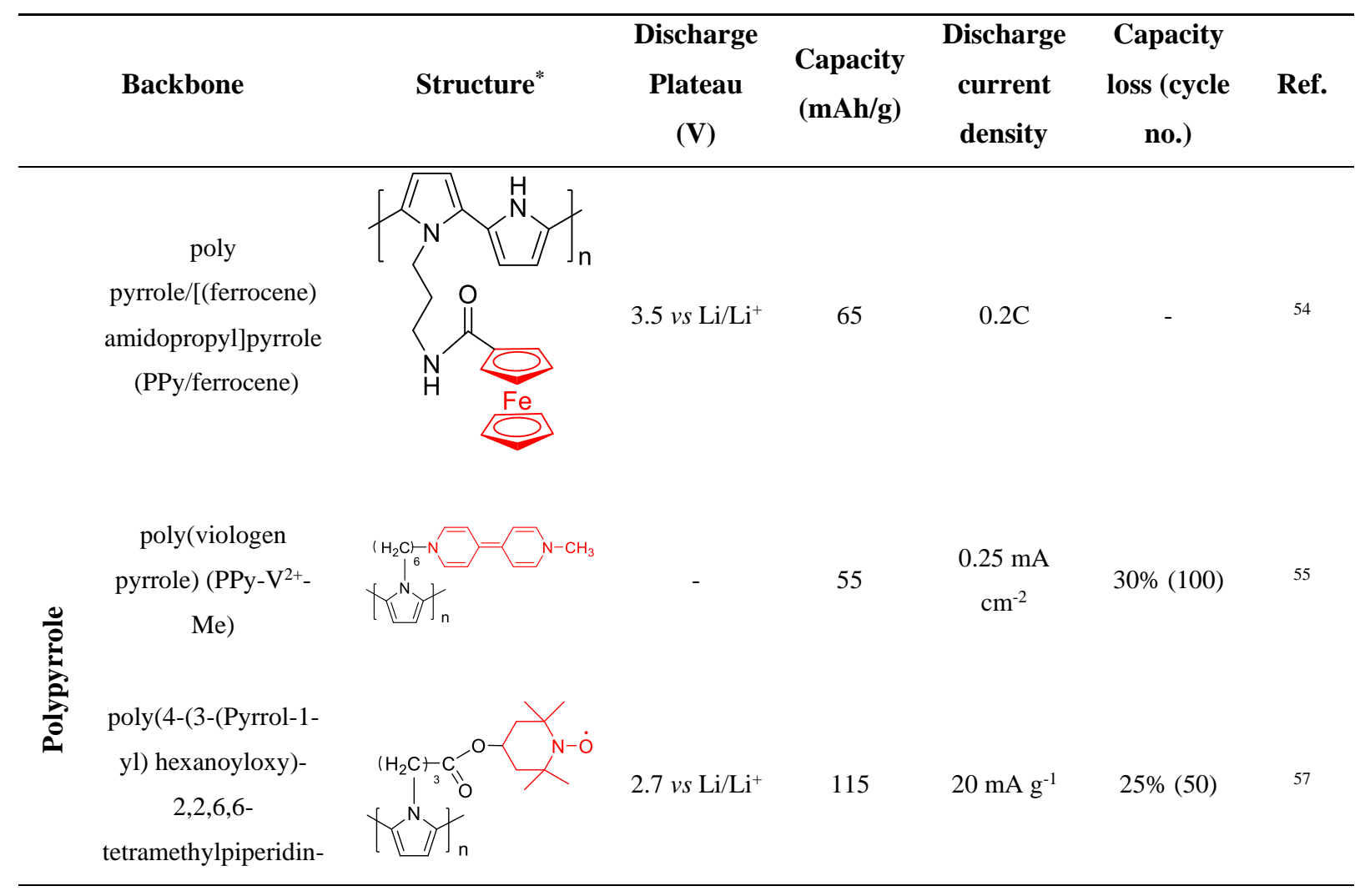




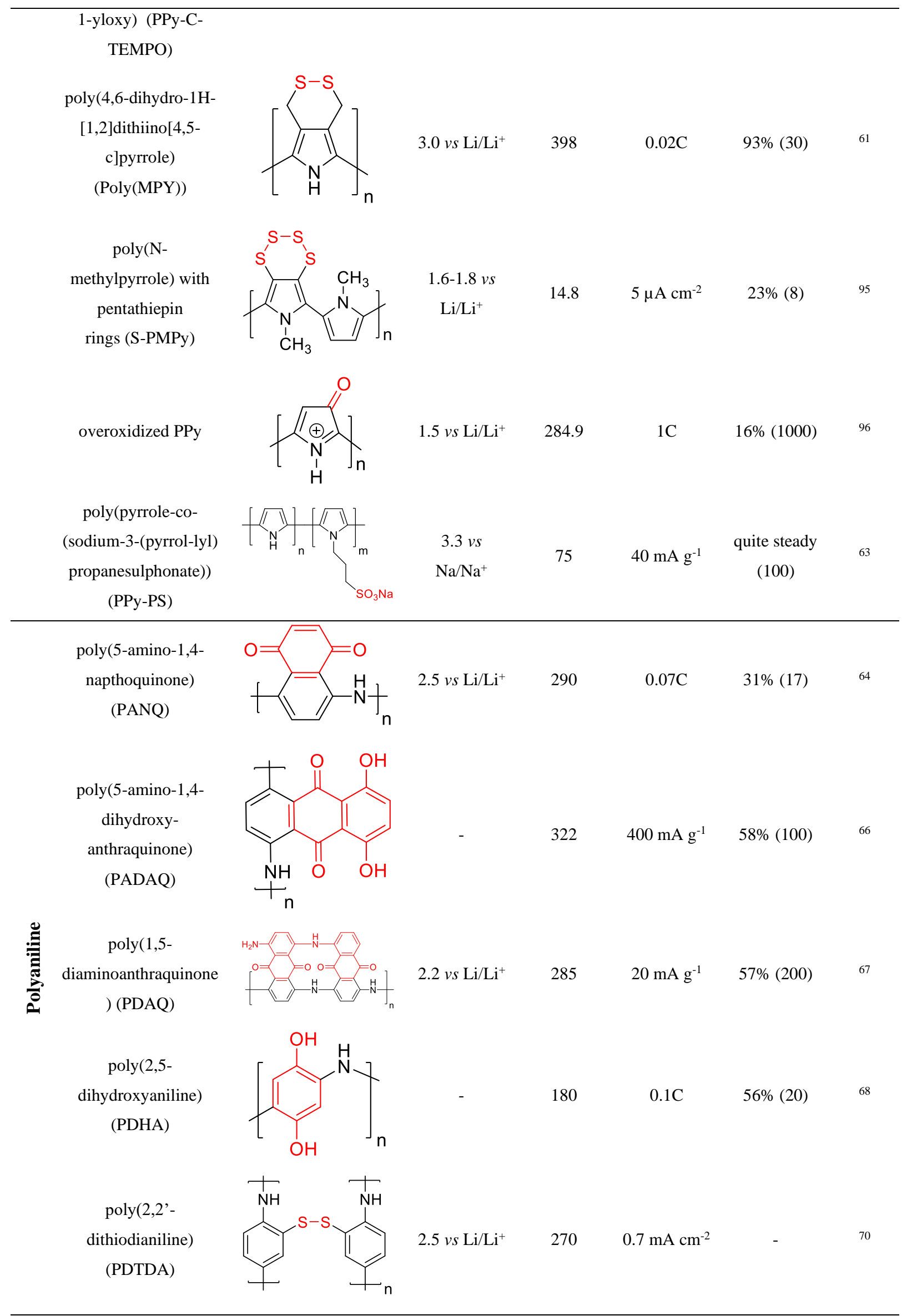




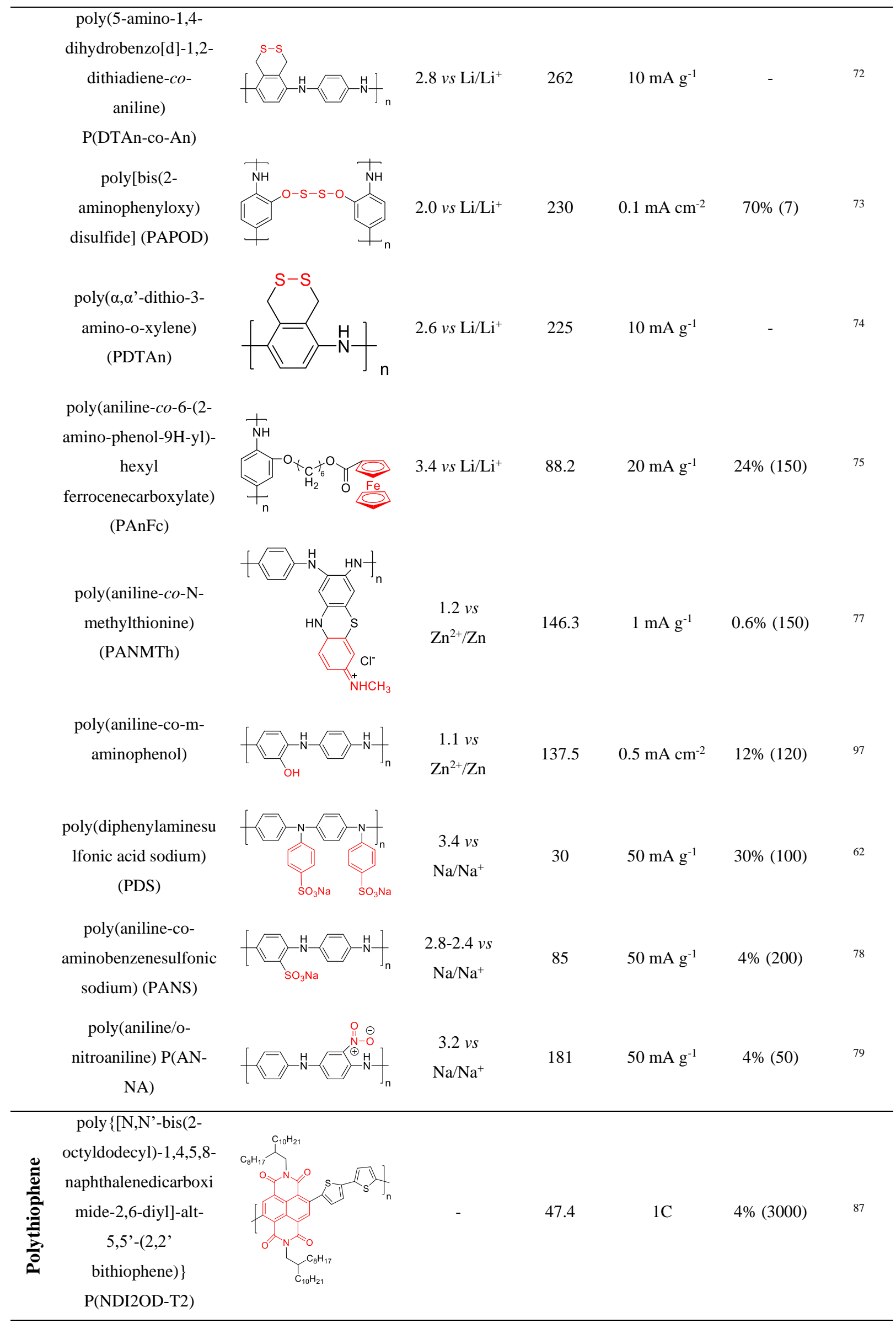




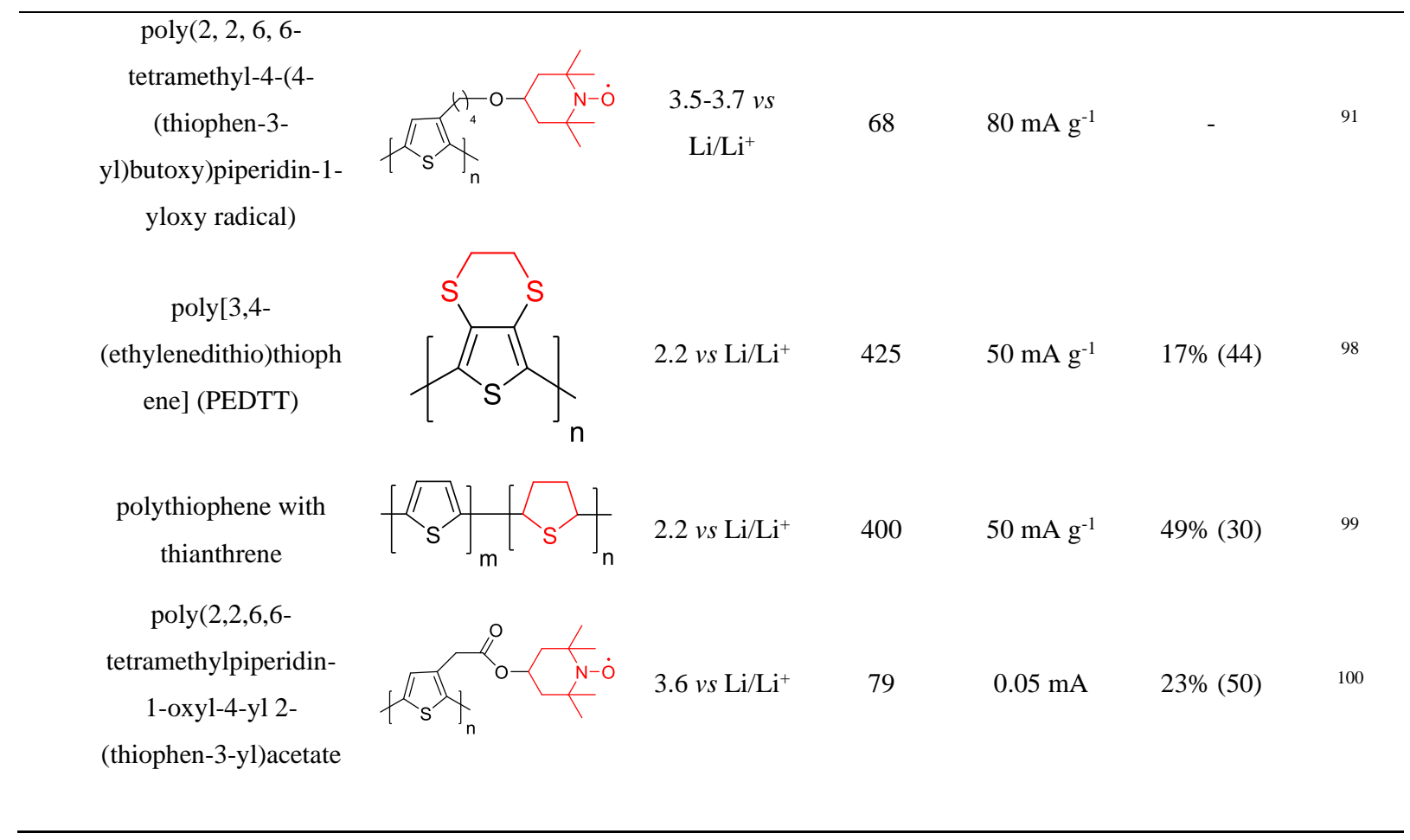

* Redox-active groups and ionizable organic anions grafted in the CPs are labelled in red.

\section{Modification with Redox-Active Dopants}

Modifying the backbone of CPs with redox-active functional groups can alleviate sluggish doping/de-doping process and improve charge storage capability. There still exists room to improve the performance by substituting those electrochemically inert dopants. For instance, the theoretical specific capacity of PPy/p-toluenesulfonate ( $p \mathrm{TS}$ ) (a 0.33 doping level, one electron transfer) is $133 \mathrm{mAh} \mathrm{g}^{-1}$ if only taking pyrrole units into account, but it is down to 73 $\mathrm{mAh} \mathrm{g}^{-1}$ with the inclusion of dopant. Thus, using redox-active dopants instead is an effective way to improve charge storage by contributing additional capacity, and/or altering the redox mechanism of CPs. The prerequisite for choosing proper dopants is that their redox potential should fall into the operation voltage range of batteries, thus to facilitate electron transport and contribute their capacity.

Hexacyanoferrate is an important iron-containing redox-active species, which can afford a strong redox couple of $\mathrm{Fe}(\mathrm{CN})_{6}{ }^{4-} / \mathrm{Fe}(\mathrm{CN})_{6}{ }^{3-}$. Torres-Gomez et al. first doped PPy with potassium hexacyanoferrate $\left(\mathrm{K}_{3} \mathrm{Fe}(\mathrm{CN})_{6}\right)$, and it displayed a specific capacity of $69 \mathrm{mAh} \mathrm{g}^{-1}$ as a cathode for LIBs. ${ }^{101}$ Zhou and co-workers fabricated $\mathrm{Fe}(\mathrm{CN}){ }_{6}{ }^{4-}$-doped PPy cathodes. ${ }^{91}$ The $\mathrm{Fe}(\mathrm{CN})_{6}{ }^{4-}$ ions served as a redox mediator to improve the charge transfer between polymer and electrolyte, as its redox potential $\left(\sim 3.0 \mathrm{~V} v s\right.$. $\left.\mathrm{Li} / \mathrm{Li}^{+}\right)$is close to the Fermi level of PPy $\left(\mathrm{E}_{\mathrm{F}}=\right.$ 
+2.50 to $\left.+2.80 \mathrm{~V} v s . \mathrm{Li} / \mathrm{Li}^{+}\right) .{ }^{102}$ The resulting PPy/FC cathodes delivered a significantly improved specific capacity of $\sim 145 \mathrm{mAh} \mathrm{g}^{-1}$ in sharp contrast to that $\sim 35 \mathrm{mAh} \mathrm{g}^{-1}$ from undoped PPy over a high potential range of 1.5-4.0 V (vs. $\left.\mathrm{Li}^{+} / \mathrm{Li}\right)$ at a current density of $50 \mathrm{~mA}$ $\mathrm{g}^{-1}$. This material also exhibited great cycling stability with a capacity retention rate of $80 \%$ over 100 cycles at $50 \mathrm{~mA} \mathrm{~g}^{-1}$. The $\mathrm{Fe}(\mathrm{CN})_{6}{ }^{4-}$-doped PPy has demonstrated the application in NIBs as well, offering a high specific capacity of $135 \mathrm{mAh} \mathrm{g}^{-1}$ at $50 \mathrm{~mA} \mathrm{~g}^{-1}$ along with an excellent capacity retention rate of $85 \%$ over 100 cycles. ${ }^{103}$

Deng et al. developed a redox-active molecule perylene-3,4,9,10-tetracharbonxydiimide (PTCDI) doped PPy. It demonstrated an oxidation/reduction pair at $+3.0 /+2.0 \mathrm{~V}\left(v s . \mathrm{Li} / \mathrm{Li}^{+}\right)$, which was derived from association/dissociation of $\mathrm{Li}^{+}$to carbonyl groups. ${ }^{104} \mathrm{PTCDI}$ has low solubility in most organic electrolytes affording an improved long-term cycling stability. This material demonstrated a high reversible capacity of $>100 \mathrm{mAh} \mathrm{g}^{-1}$ at a current density of 50 $\mathrm{mA} \mathrm{g}^{-1}$, and a high capacity retention rate of $92 \%$ over 200 cycles. Diphenylamine-4-sulfonate (DS) displayed two reversible redox reactions in the $\mathrm{Na}^{+}$-containing electrolyte, 3.5-3.8 $\mathrm{V}$ and 3.3-3.6 V in the anodic and cathodic processes, respectively. ${ }^{105}$ The resulting DS-doped PPy cathode displayed the redox behavior of DS anions and PPy chains, affording a large reversible specific capacity of $115 \mathrm{mAh} \mathrm{g}^{-1}$ at $50 \mathrm{~mA} \mathrm{~g}^{-1}$ as a cathode in SIBs.

Water-soluble poly(2-methoxyaniline-5-sulfonic acid) (PMAS) has a free negatively charged sulfonate group per dimer unit, that can be incorporated into CP matrices as a dopant. ${ }^{106}$ Yang et al. reported the Li storage properties of an electrochemically synthesized PMAS-doped PPy electrode. ${ }^{107}$ PMAS as the supramolecular pre-order template can guide the growth of PPy resulting in the formation of a film with a very smooth surface other than the typical cauliflower morphology. PMAS showed its own redox activity in this composite, as revealed by the redox pairs $\left(\mathrm{E} / \mathrm{E}^{\prime}\right.$ and $\left.\mathrm{P} / \mathrm{P}^{\prime}\right)$ when scanned over 2.0 - $4.0 \mathrm{~V}$ vs. $\mathrm{Li} / \mathrm{Li}^{+}$. These peaks are related to the transition between different states of PMAS. Moreover, PMAS with such large molecular size was confined within the polymer matrix and became immobile, migration of smaller size cations $\left(\mathrm{Li}^{+}\right)$dominated in the charge/discharge process. The swelling and shrinking of PPy could be alleviated resulting in improved cycling stability. Benefiting from both the redox activity of PMAS and the intercalation/deintercalation of smaller size $\mathrm{Li}^{+}$, the resultant PPy/PMAS exhibited a greatly improved capacity of $120.6 \mathrm{mAh} \mathrm{g}^{-1}$ at $0.1 \mathrm{~A} \mathrm{~g}^{-1}$ as well as a high capacity retention rate of about $88.5 \%$ over 800 cycles at $1 \mathrm{~A} \mathrm{~g}^{-1}$; in sharp contrast to the capacity of $81 \mathrm{mAh} \mathrm{g}^{-1}$ and retention rate of $67.1 \%$ for PPy/pTS. 
Various types of redox-active organic anions have been employed as dopants. Yoneyama et al. doped anthraquinone-1-sulfonate (AQS) ions into PPy films. The redox reactions of AQS generally involves an enolization reaction and a reverse reaction of carbonyl group: $\mathrm{AQ}-\mathrm{SO}_{3}{ }^{-}$ /AQ ${ }^{-}-\mathrm{SO}_{3}{ }^{-}$and $\mathrm{AQ}^{-}-\mathrm{SO}_{3}{ }^{-} / \mathrm{AQ}^{2-}-\mathrm{SO}_{3}{ }^{-}$, as evidenced by the additional redox peaks at -0.93 and -1.16 V vs. SCE in the cyclic voltammograms compared with PPy doped with sodium naphthalene-1-sulfonate (NtS). The AQS-doped PPy films showed a higher energy density of $150 \mathrm{mAh} \mathrm{mL} \mathrm{m}^{-1}$, which is more than twice that delivered from PPy films doped with electrochemically inactive anions such as $\mathrm{NtS}$ or $\mathrm{ClO}_{4}{ }^{-1} \cdot{ }^{108}$ The incorporation of a second dopant, reduced graphene oxide (rGO), into PPy/AQS can further increase the charge storage by creating an interconnected porous structure. This structure was formed due to the overlapping of large graphene nanosheets that were used as templates and dopants during the growth of PPy. ${ }^{109}$ This composite exhibited an improved capacity of $127.2 \mathrm{mAh} \mathrm{g}^{-1}$ with ca. $100 \%$ coulombic efficiency at $0.1 \mathrm{~A} \mathrm{~g}^{-1}$ over 500 cycles in a lithium battery. Such excellent performance is ascribed to the efficient pathway for ions and electrons transport within the porous structure. Lignosulfonate, a lignin derivative containing quinone groups, is a by-product of pulp and paper processing. It can be applied as dopant to be incorporated with PPy matrix. Quinone groups of lignosulfonate can be electrochemically reduced from its $\mathrm{Q}$ form (quinone) to its $\mathrm{QH}_{2}$ form (phenol) along with the reduction of PPy (Figure 5a). Large amounts of quinone groups in this biopolymer effectively improved the charge storage by contributing an additional capacity of $\sim 40 \mathrm{mAh} \mathrm{g}^{-1}$ on top of PPy's $30-35 \mathrm{mAh} \mathrm{g}^{-1}$ (Figure $5 \mathrm{~b}$ ). ${ }^{110}$ This work is of significance since it demonstrates the utilisation of industrial waste for fabricating battery electrode materials.

Redox-active molecules doped PANI has demonstrated improved electrochemical properties as well. Yamamoto and co-workers performed a systematic research on PANI integrated with redox-active dopants including ferrocene sulfonic acid $(\mathrm{FcS})$, hydroquinone sulfonic acid (HQS), and naphthoquinone sulfonic acid (NQS). ${ }^{111}$ Owing to their inherent redox activities, these dopants all contributed additional electrochemical performance to the composite. As a result, PANI doped with HQS and NQS respectively showed a higher capacity of 104 and 96 $\mathrm{mAh} \mathrm{g}^{-1}$ in the cell using zinc as an auxiliary electrode, while PANI doped with electrochemically inert $\mathrm{ClO}_{4}^{-}$delivered a capacity of $84 \mathrm{mAh} \mathrm{g}^{-1}$. PANI has also been applied as a cathode for aqueous rechargeable zinc-ion batteries with the combined $\mathrm{Zn}^{2+}$ insertion/extraction and dual-ion mechanisms. ${ }^{112}$ Recently, Sun and co-workers reported the synthesis of sulfo self-doped PANI (PANI-S) nanorods with diameter and length of $\sim 50$ and 
$\sim 200 \mathrm{~nm}$, through a facile electrochemical copolymerization. ${ }^{113}$ As supported by the X-ray photoelectron spectroscopy characterization, PANI-S showed the ability to work as an organic reservoir to store multiple ions including the electrolyte species such as $\mathrm{SO}_{4}{ }^{2-}$ and $\mathrm{Zn}^{2+}$, as well as protons $\left(\mathrm{H}^{+}\right)$(Figure $5 \mathrm{c}$ ). Resulting from this unique mechanism, the PANI-S/Zn cell produced a capacity of $184 \mathrm{mAh} \mathrm{g}^{-1}$ at $0.2 \mathrm{~A} \mathrm{~g}^{-1}$ (Figure 5d). A high capacity of $110 \mathrm{mAh} \mathrm{g}^{-1}$ was still maintained at $10 \mathrm{~A} \mathrm{~g}^{-1}$ after 2,000 cycles. In contrast, the undoped PANI suffered from sharp capacity fading during the cycling.
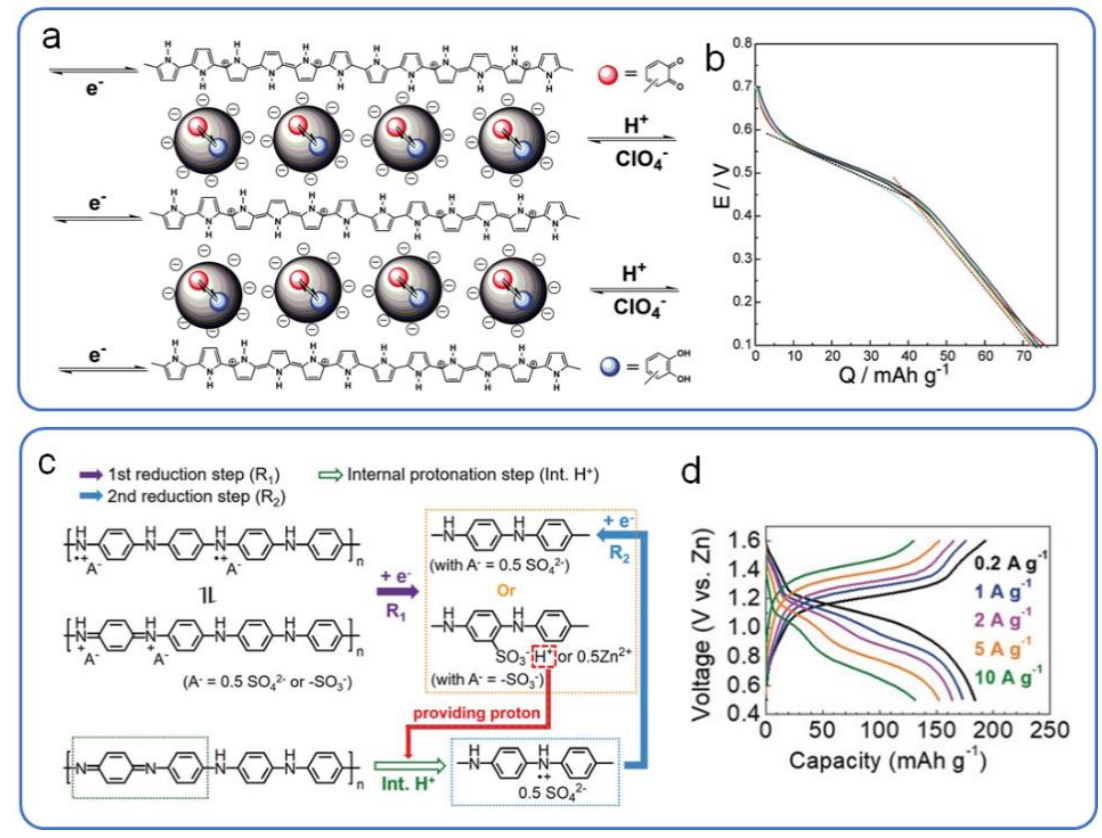

Figure 5 (a) The redox reaction of quinone functional groups in lignosulfonate within a PPy matrix; (b) Galvanostatic discharge curves of PPy/lignin film in $0.1 \mathrm{M} \mathrm{HClO}_{4}$ at current densities from 0.83 to $16.7 \mathrm{~A} \mathrm{~g}^{-1}$; (Reproduced with permission from ref. 110. Copyright 2012, American Association for the Advancement of Science). (c) Proposed mechanism and structures of PANI-S upon charging (oxidation) and discharging (reduction) versus Zn metal; (d) Charge and discharge profiles of PANI-S/Zn cell at different current densities; (Reproduced with permission from ref. 113. Copyright 2018, Wiley-VCH Verlag GmbH \& Co. KGaA.).

In summary, incorporating redox-active dopants into CPs has been demonstrated to be an effective approach for enhancing electrochemical performance. These dopants demonstrate their inherent electrochemical properties in addition to those from CPs. They contribute additional charge storage when applied in battery applications. Future work may focus on the development of new redox-active dopants and doping methods to achieve higher doping level 
for enhanced redox capacity. An overview of this type of CPs and their energy storage properties are summarized in Table 2.

Table 2 Overview of Conducting Polymers Doped with Redox-Active Dopants for Secondary Batteries.

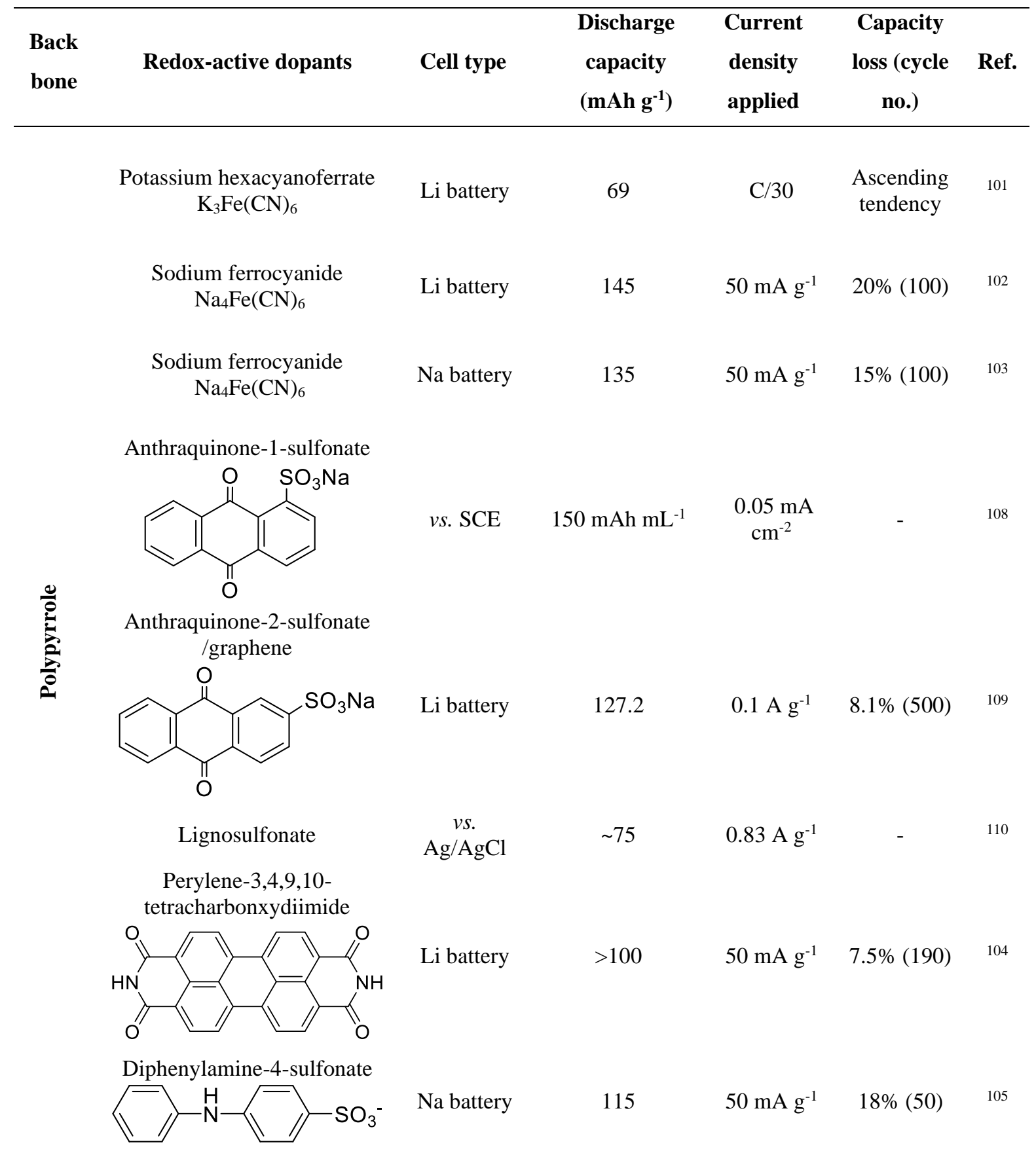


Poly(2-methoxyaniline-5sulfonic acid)

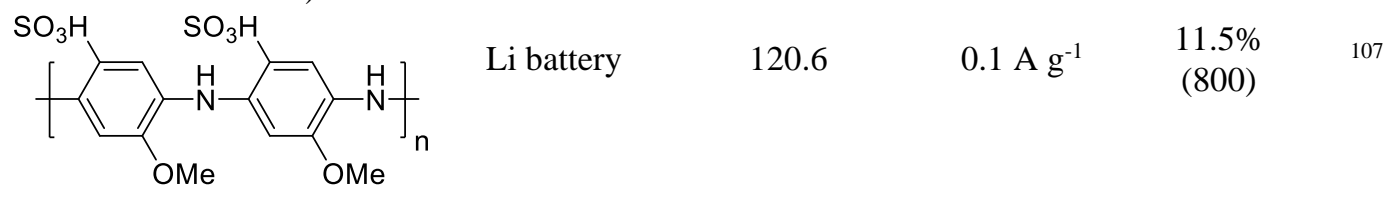

Ferrocene sulfonic acid
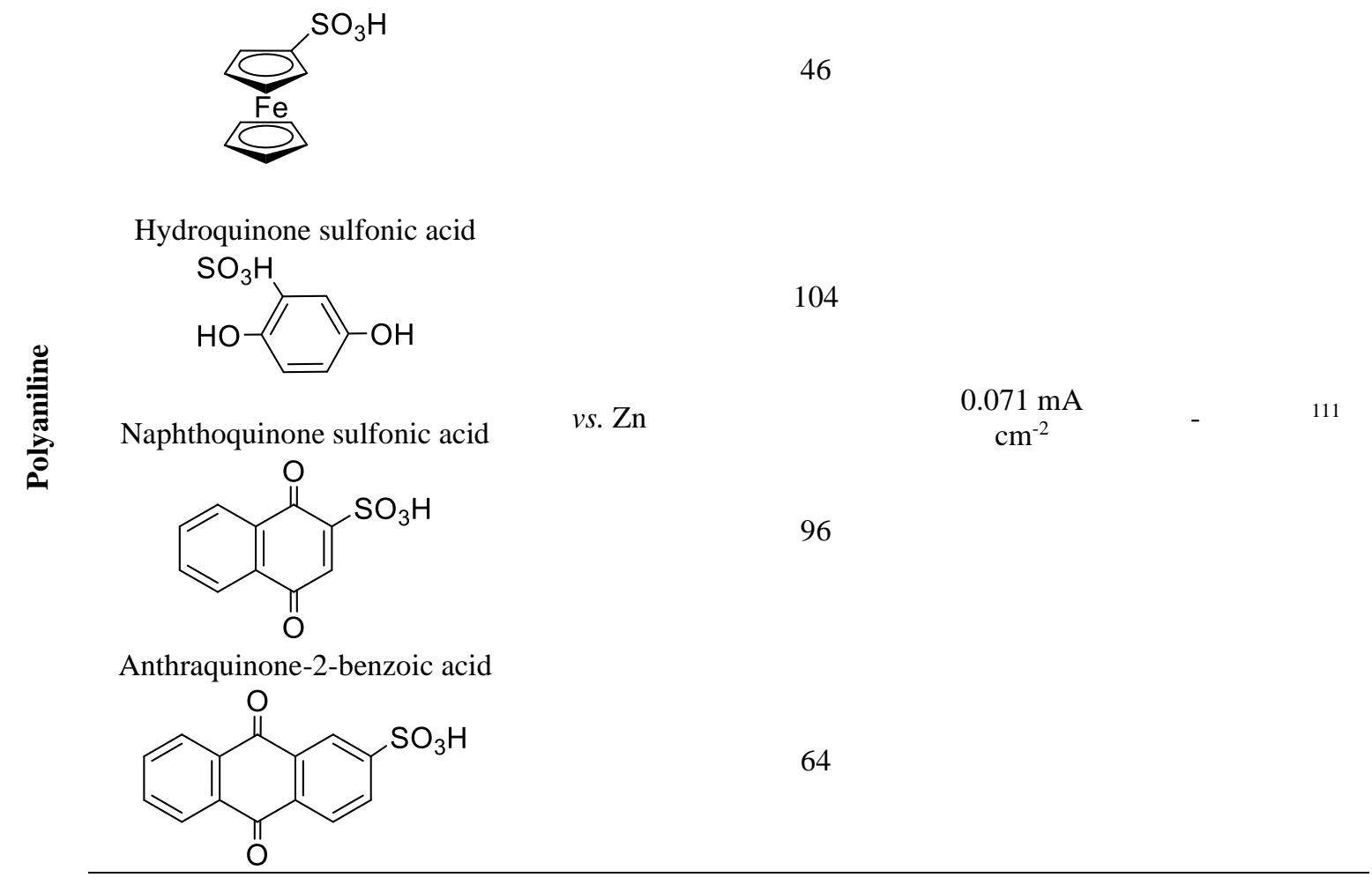

\section{All-Polymer Batteries}

Herein all-polymer batteries mean that cathode and anode electrodes are all based on CPs. They are free of metal-containing electrodes, thereby enabling a lightweight, flexible, environmentally benign and sustainable battery system. This system utilizes capacity-carrying polymeric materials as both anodes and cathodes, in which cations and/or anions move between electrodes in a rocking-chair motion to compensate the charge. ${ }^{114}$

\section{n-Doped Conducting Polymer Electrode}

In an ideal all-polymer battery, p-type polymer with higher redox potentials function as a cathode in combination with a n-type polymer anode. ${ }^{81}$ However, limited n-type CPs are available owing to their poor chemical stability and large impedance. ${ }^{115}$ In 1997, Searson et al. pioneered this field by coupling PTh electrodes bearing different fluorine-containing 
aromatic rings with a polymer gel electrolyte. ${ }^{116}$ The maximum n-doping level of functional PTh was found to be correlated with the number of fluorine atoms on the phenyl ring. The assembled all-polymer dual-ion battery exhibited a discharge voltage of $\sim 2.5 \mathrm{~V}$ and a capacity of 9.5-11.5 mAh g $\mathrm{g}^{-1}$ in the electrolyte of tetrabutylammonium tetrafluoroborate. Recently, several n-type conjugated redox polymers based on 5-alkyl-thieno[3,4-c]pyrrole-4,6-dione have been developed (Figure 6a). ${ }^{117}$ The effect of carbonyl group, alkyl chain and comonomer unit on the electrochemical activity of these polymers has been demonstrated. Incorporating an electron-withdrawing or electron-donating group with the conjugated backbone of polymer had a profound impact on its redox potential, which could vary over a range of $400 \mathrm{mV}$. The polymer with a redox potential of $1.55 \mathrm{~V} v s . \mathrm{Li} / \mathrm{Li}^{+}$is suitable for application in a lithium-ion battery as an anode (Figure 6b).

Except those PThs, Jimenez et al. recently developed a lithium n-doped PANI for Li battery. ${ }^{118}$ Multiple redox states are involved in the protonation and deprotonation equilibrium of PANI, including the completely reduced leucoemeraldine base (LB), conducting emeraldine salt form (ES), and fully oxidized pernigraniline base (PNB). ${ }^{119}$ Research of PANI commonly centres on p-doped states (transitions from LB to ES, then ES to PNB) which involves simple acid-base reactions in water or protic media (Figure 6c). The deprotonation-induced n-doped of PANI needs cations, such as $\mathrm{Na}^{+}$and $\mathrm{K}^{+}$, to compensate for the negatively charged nitrogen atoms. ${ }^{120}$ Li-doped PANI (lithium emeraldinate) was prepared vis a lithium-proton exchange on the emeraldine base (EB) in an anhydrous lithium-based electrolyte, since the EB form had distinct interaction with Li cations (Figure 7d). This lithium emeraldinate positive electrode can be discharged to $4.25 \mathrm{~V} v s$. $\mathrm{Li}^{+} / \mathrm{Li}$ and displayed a coulombic efficiency of $99 \%$ after 400 cycles. The assembled cell delivered a specific capacity of $208 \mathrm{mAh} \mathrm{g}^{-1}$ at $1 / 10 \mathrm{C}$, corresponding to $90.4 \%$ of its theoretical capacity. This lithium n-doped PANI shows the best performance in terms of high specific capacity and cycling stability in LIBs in this review.

Other conjugated polymers with homogeneous microporous structure have been used as a $\mathrm{Li} / \mathrm{Na} \mathrm{n}$-doped electrode. A conjugated microporous polymer, 4,7-dicarbazyl-[2,1,3]benzothiadiazole (PDCzBT), was synthesized via oxidative coupling polymerization. ${ }^{121}$ This polymer showed an ultrahigh specific surface area providing abundant active sites for storage. Uniform microporous structure is beneficial for the rapid transport of electrons and ions. A high discharge capacity of $1042 \mathrm{mAh} \mathrm{g}^{-1}$ was delivered after 5 cycles, which may be ascribed to the mixed processes involving the Li doping and absorbing at the surface/interface. 


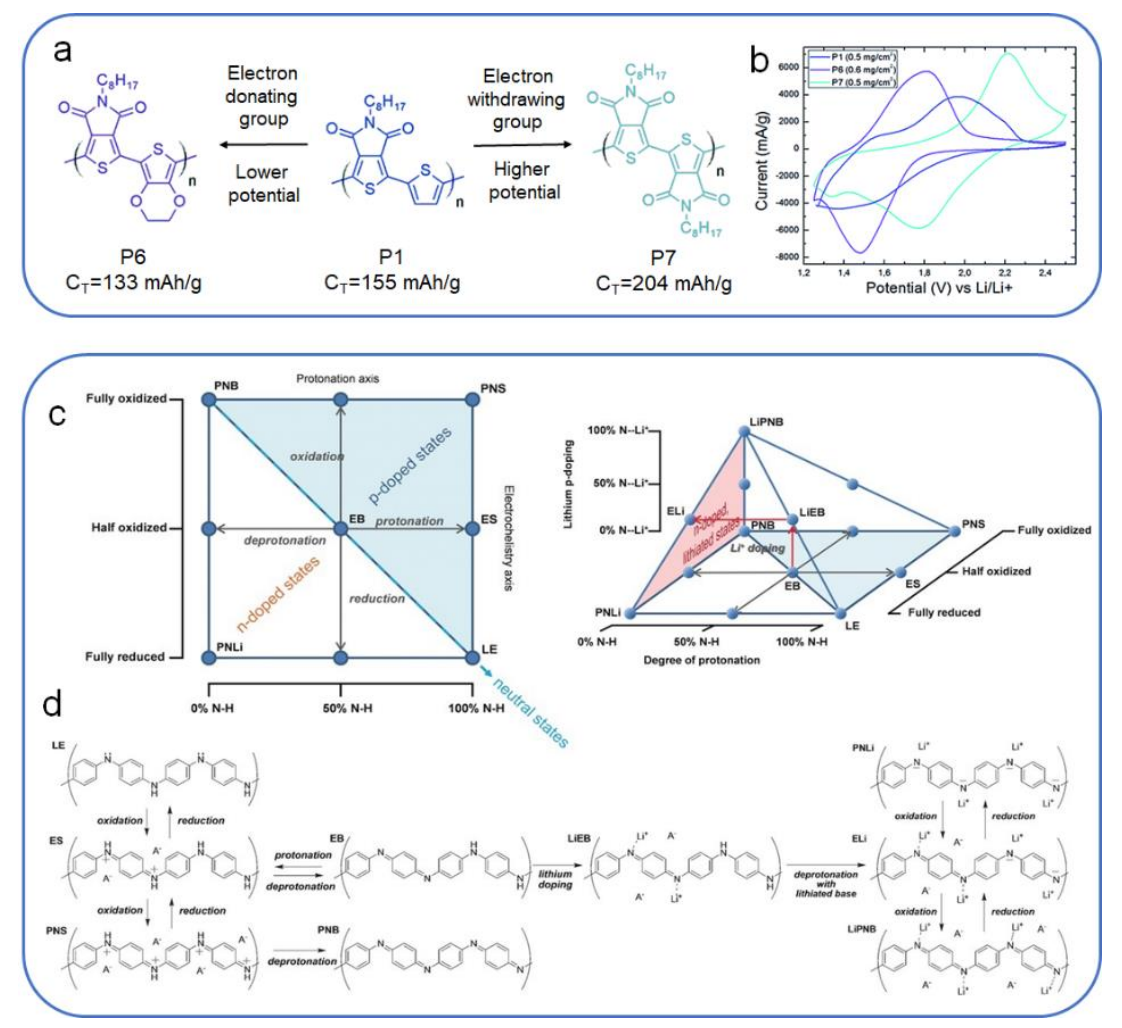

Figure 6 (a) Structure and theoretical capacities of n-type poly(5-alkyl-thieno[3,4-c]pyrrole4,6-dione); (b) Cyclic voltammograms of n-type conjugated redox polymers; (Reproduced with permission from ref. 117. Copyright 2017, Royal Society of Chemistry). (c) Diagram showing the possible protonation and oxidation degrees of PANI and lithium n-doped states; (d) The formulae and reactions of PANI at different states, including the deprotonated-lithiated states (right); (Reproduced with permission from ref. 118. Copyright 2017, WILEY-VCH Verlag GmbH \& Co. KGaA, Weinheim).

\section{p-Doped Conducting Polymer Electrode}

Currently the research on all-polymer batteries still mainly focus on using p-type CPs as both cathode and anode. An early attempt involved the use of PPy doped with large polymeric anion (polystyrenesulfonate, PSS) as a "pseudo n-dopable" anode. ${ }^{122}$ The charge compensation by cation $\left(\mathrm{Li}^{+}\right)$transport instead of PSS anions caused a negative shift in the oxidation potential, thus realized a voltage separation between PPy cathode at the reduced form and anode at the oxidized form. This system exhibited a specific charge capacity of $22 \mathrm{mAh} \mathrm{g}^{-1}$, and no capacity loss over 100 cycles. Using PPy doped with different redox-active organic anions in an allpolymer battery system was demonstrated in $2006 .{ }^{123}$ The dopants used for cathode and anode materials were indigo carmine (IC) and 2,2'-azino-bis(3-ethylbenzothiazoline-6-sulfonate) (ABTS), respectively. Both PPy/IC and PPy/ABTS exhibited large faradaic current response 
over the applied potential range of $-0.1 \mathrm{~V}$ to $0.8 \mathrm{~V}$ like neat dopants. The potential difference generated between these two redox reactions allowed them to perform as cathode and anode. The final full cell displayed a specific capacity of $15 \mathrm{mAh} \mathrm{g}^{-1}$, which was equal to the estimated theoretical capacity. An all-polymer battery composed of free-standing electrodeposited PPy film electrodes has also been demonstrated, which provides a step forward towards the development of flexible all-polymer battery system. ${ }^{124}$ PPy film doped with IC and $p$ TS functioned as anode and cathode, respectively. This battery system displayed an initial discharge capacity of $21 \mathrm{mAh} \mathrm{g}^{-1}$, a capacity retention rate of $76 \%$ over 50 cycles.

Like PPy, a potential difference can also be generated between the neutral state and an oxidized state (p-doped) for PEDOT, thus enabling the realisation of an all-polymer battery. ${ }^{125}$ PEDOT has shown catalytic ability to oxygen reduction reaction. ${ }^{126}$ Thus, a PEDOT-air battery was fabricated with polyethyleneimine (PEI) coated PEDOT/PSS anode and PEDOT/PSS cathode. During discharge, the PEI layer was consumed at the anode and $\mathrm{O}_{2}$ was reduced at the PEDOT cathode, producing an open circuit voltage of about $0.5 \mathrm{~V} .{ }^{127}$ An optimized oxidation level of the PEDOT anode with a high electrical conductivity could be achieved by simply soaking it into mixtures of 1,8-diazabicyclo[5.4.0] undec-7-ene and dimethyl sulfoxide. ${ }^{128}$ The assembled battery with a PEI-PEDOT/PSS anode and PEDOT/PSS cathode presented a discharge capacity of $0.02 \mathrm{mAh}$ and an output power of $1.2 \mu \mathrm{W}$ in the electrolyte of PSSNa.

Sjödin et al. recently demonstrated an all-polymer proton battery composed of PEDOT functionalized with anthraquinone (PEDOT-AQ) or benzoquinone (PEDOT-BQ) pendant groups as negative and positive electrode materials, respectively (Figure 7a). ${ }^{129}$ The electrolyte containing proton donor and acceptor allowed the $2 \mathrm{e}^{-} / 2 \mathrm{H}^{+}$quinone/hydroquinone redox reaction, and enabled the PEDOT backbone to be conductive in the potential region of quinone redox reaction. This all-polymer proton battery delivered a capacity of $120 \mathrm{mAh} \mathrm{g}^{-1}$ with an average cell potential of $0.5 \mathrm{~V}$ based on PEDOT-BQ, $75 \%$ of its theoretical specific capacity (Figure 7b). They further developed two CRPs based on PEDOT with a hydroquinone pendant group. ${ }^{130}$ The hydroquinone pendant group underwent stable proton cycling. These polymers showed fast redox conversion, making them suitable for aqueous rechargeable all-polymer battery. 

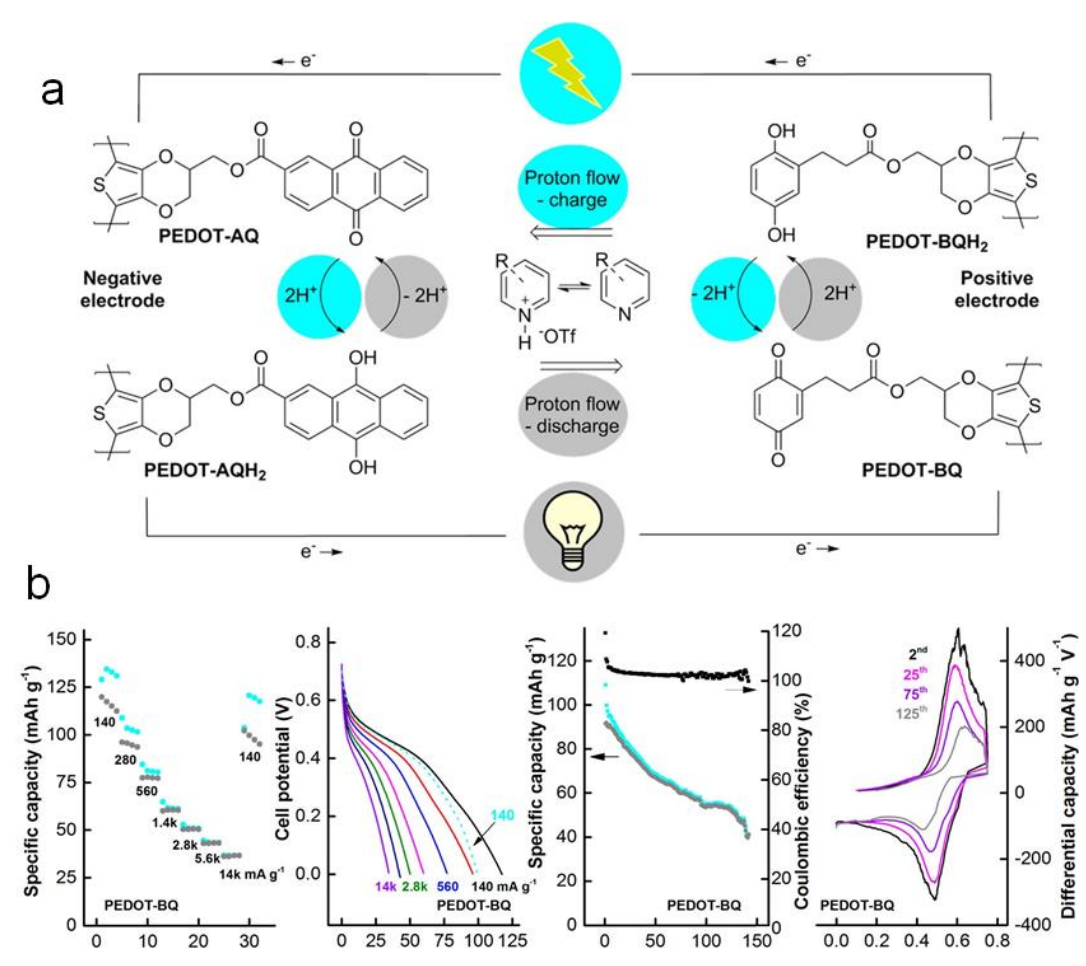

Figure 7 (a) Depiction of PEDOT-AQ, PEDOT-BQ, pyridine-based proton donors and acceptors (electrolyte), redox reactions occurred during charge (cyan) and discharge (gray) in an all-polymer battery; (b) Cell characteristics measured in a two-electrode setup with PEDOTBQ as limiting material. (Reproduced with permission from ref. 129. Copyright 2017, American Chemical Society).

Another type of stable all-polymer battery system was developed by Wang et al. using functionalized p-doped PTh and PPy as anode and cathode, respectively. ${ }^{131}$ The anode was prepared by directly casting undoped neutral poly(styryl-substituted dialkoxyterthiophene) from chloroform solution on carbon-fiber mats or $\mathrm{Ni} / \mathrm{Cu}$-coated non-woven polyester substrate. This battery showed a high discharge efficiency of over $94 \%$ and a discharge capacity of 39.1 mAh $\mathrm{g}^{-1}$. They also demonstrated a similar all-polymer battery system but with electropolymerized poly(4,4'-didecyloxyterthiophene) on $\mathrm{Ni} / \mathrm{Cu}$-coated fabric substrate as the anode, which afforded a discharge capacity of $94.7 \mathrm{mAh} \mathrm{g}^{-1} .132$

\section{Conducting Polymers in Cytocompatible/Biodegradable Metal-Air} Bioelectric Batteries

\section{Metal-air Bioelectric Batteries}


Implantable medical devices (IMDs) have been widely used for therapies serving as functional devices to detect, prevent and cure diseases challenging human life. ${ }^{133-135}$ Currently, Li batteries are the predominant power sources to power IMDs since the first implantation of lithium iodine batteries for cardiac pacemakers in $1972 .{ }^{136}$ Inevitably, Li batteries contain toxic chemicals which hamper their deployment with biomedical applications. ${ }^{137}$ A bioelectric battery (bio-battery) with biocompatible electrodes that utilize body fluid as electrolyte is safe for implantation. ${ }^{138}$ It is a type of metal-air battery that consists of a cathode for oxygen reduction reaction (ORR) and a sacrificial anode. The anode can be a biocompatible and bioresorbable metal, such as magnesium $(\mathrm{Mg})$, zinc $(\mathrm{Zn})$ and their alloys. ${ }^{139}$

CPs with good electrical conductivity and electrocatalytic activity towards oxygen reduction have attracted attention as cathode materials in metal-air batteries. ${ }^{140}$ In 2005 , V. G. Khomenko et al. discussed the mechanism and feasibility of various types of CPs as ORR catalyst in acid and neutral electrolyte. ${ }^{141,142}$ They proposed an "oxygen absorption" theory that molecular oxygen can be absorbed by the carbon atoms on the polymer chain to form an "oxygenconductive polymer" bridging complex. This bridging complex could weaken the $\mathrm{O}-\mathrm{O}$ bond of oxygen and lower the activation energy for reduction, leading to the electrocatalytic activity. In an $\mathrm{Mg}$-air bio-battery, $\mathrm{Mg}$ anode is oxidized to $\mathrm{Mg}^{2+}$ and donates electrons when discharged; the CPs cathode, taking oxidized PPy as an example, takes up electrons and is reduced concomitantly and then the reduced PPy is re-oxidized ('recharged') by oxygen as illustrated in Figure 8. ${ }^{143}$ The ORR mechanism in PEDOT has also been revealed using the density functional theory. ${ }^{141}$ Its catalytic activity is proposed to be related to the formation of polaronic states, which leads to the decreased HOMO-LUMO gap and an enhanced reactivity. In a recent study, the doping of polymer by oxygen during ORR was convinced by decoupling the conductivity (intrinsic property) from electrocatalysis (an extrinsic phenomenon). ${ }^{144}$ Hence, the PEDOT electrode is electrochemically reduced (undoped) in the voltage range of ORR regime, but $\mathrm{O}_{2}$ keeps it conducting; ensuring PEDOT to act as an electrode for the ORR.

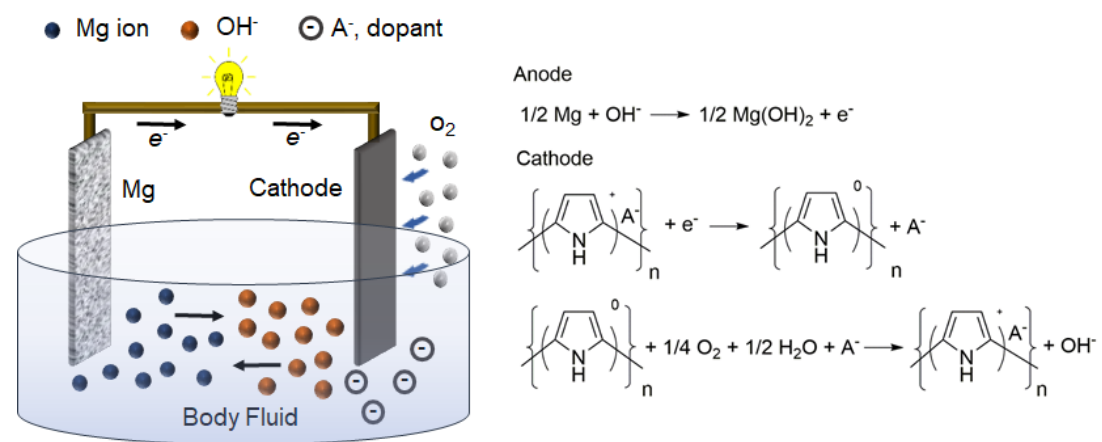


Figure 8 Schematic working principle and general redox chemistries of a Mg-air bio-battery using PPy cathode when being discharged ( $\mathrm{A}^{-}$represents mobile charge balance anions).

\section{Cytocompatible Conducting Polymer Electrodes}

Electrodes should be cyto- and tissue-compatible for applications in bio-batteries. CPs, particularly PPy and PEDOT, are biocompatible with various cell types and tissues and have been thoroughly evaluated as biomaterials both in vitro and in vivo. ${ }^{145}$ They have demonstrated excellent cytocompatibility for supporting the in-vitro adhesion, growth and differentiation of a wide range of cell types such as bone, neural, glial, rat pheochromocytoma and endothelial cells, fibroblasts, keratinocytes and mesenchymal stem cells. ${ }^{146}$ PPy also showed good tissuecompatibility in animal models with no significant long-term adverse effect in vivo or inducing only a minimal tissue response. ${ }^{147}$ It should be pointed out that the cytocompatibility of CPs depends on their surface charge, surface properties (i.e., roughness, morphology, wettability), and stiffness as well; all these are closely related with the polymerization methods and conditions used. ${ }^{148}$ The cytocompatibility can be improved by removing the impurities such as unused reactants and monomers as well as the produced short oligomers. Additionally, the integration with bioactive molecules (e.g., polysaccharides, proteins, and even whole living cells) can further modulate the biological functionality of CPs, which can be achieved by physical approach (entrapping, blending) and chemical approach (doping, covalent attaching). ${ }^{149}$ Dopants form a major constituent of a $\mathrm{CP}$, and hence affect its inherent chemicalbiological properties. PPy doped with different biomolecules have demonstrated efficacy for biomedical applications, such as dermatan sulphate for increasing keratinocyte viability, heparin for increasing the proliferation of endothelial cells, and laminin-derived peptides to control neuron and astrocyte adhesion. ${ }^{150,151}$

PPy cathode (doped with a biomolecule, dextran sulfate) coupled with a bioresorbable Mg alloy anode could maintain a cell voltage of about $1.4 \mathrm{~V}$ for $19 \mathrm{~h}$ at a current density of $30 \mathrm{~mA} \mathrm{~g}^{-1}$ in phosphate buffered saline (PBS) electrolyte. ${ }^{152}$ Incorporating a biocompatible dopant with an electrocatalytic ability to ORR can further improve the performance. The molecule AQS with ORR capability was co-doped with reduced graphene oxide (r-GO) into PPy matrix. ${ }^{153}$ The formed PPy/AQS/r-GO composite delivered a maximum power density of $6240.5 \mathrm{~mW} \mathrm{~m}^{-2}$ in PBS, 14.2 times higher than that of PPy/pTS. The mechanical properties of CPs can also be manipulated to match that of body tissue (2-30 kPa). A two components conducting polymerbased hydrogel was developed via electrodepositing PPy onto an ionically crosslinked PEDOT 
hydrogel with $\mathrm{Mg}^{2+}$ (Figure 9a). ${ }^{154}$ It demonstrated the joint merits of conductivity and electroactivity of CPs and "soft nature" of a hydrogel, making it a versatile platform for tissue engineering and energy storage applications (Figure 9b). This cytocompatible PPy/PEDOT hydrogel coupled with an $\mathrm{Mg}$ anode provided a stable voltage of $0.7 \mathrm{~V}$ for about $160 \mathrm{~h}$ at a current density of $200 \mu \mathrm{A} \mathrm{cm}^{-2}$, affording a capacity of $32 \mathrm{mAh} \mathrm{cm}^{-2}$ and an energy density of $22 \mathrm{mWh} \mathrm{cm}^{-2}$ in PBS electrolyte (Figure 9c).

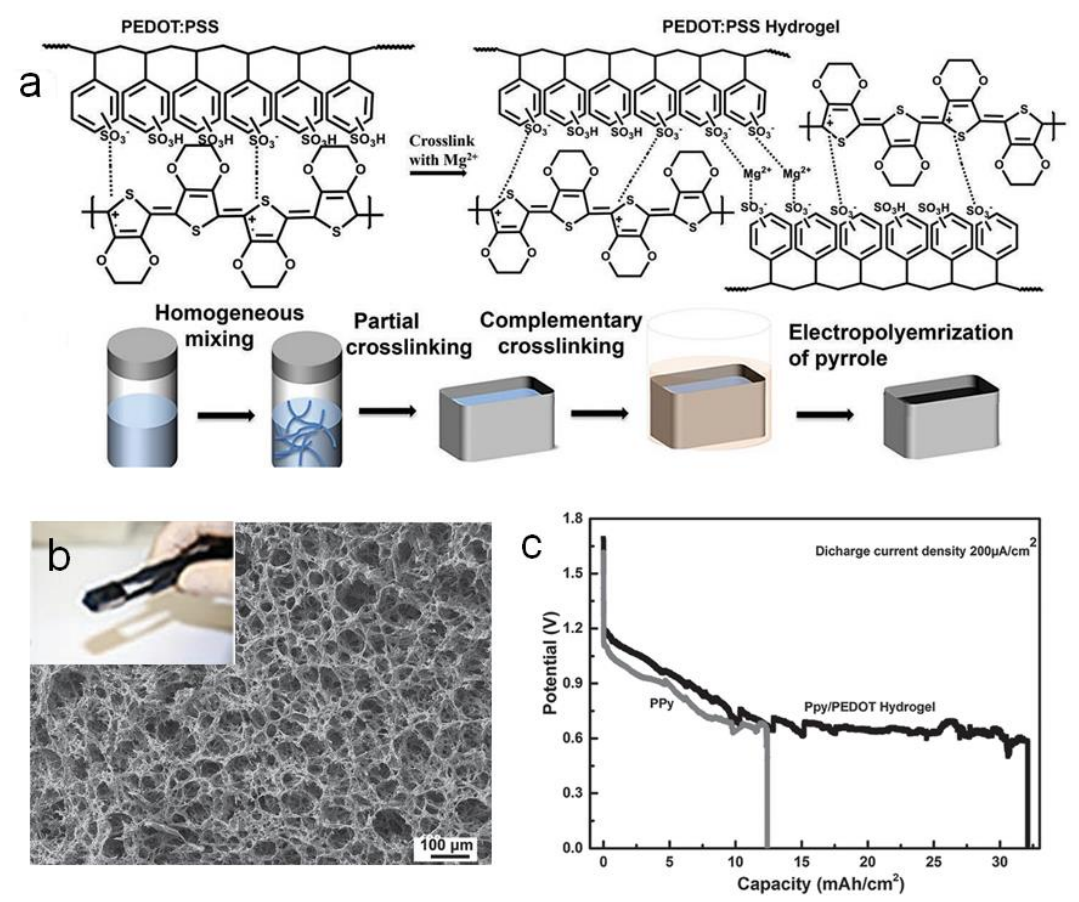

Figure 9 (a) Crosslinking process of PEDOT-PSS hydrogel and schematic procedures to fabricate PEDOT hydrogel and PPy/PEDOT hydrogel; (b) Cross-sectional and digital (inset) images of PPy/PEDOT hydrogel; (c) Discharge curves of a Mg bio-battery with a PPy/PEDOT hydrogel or a PPy cathode at $200 \mu \mathrm{A} \mathrm{cm}^{-2}$ in PBS; (Reproduced with permission from ref. 154. Copyright 2016, WILEY-VCH Verlag GmbH \& Co. KGaA, Weinheim).

\section{Biodegradable Conducting Polymer Electrodes}

A biodegradable battery system is an ideal choice to provide the energy for the emerging transient implants. ${ }^{155,156}$ They facilitate biological processes that enable/facilitate repair of damaged tissue by supporting biological processes in a controlled fashion. ${ }^{157,}{ }^{158}$ However, CPs are stable under physiological conditions and, therefore, they need to be modified to attain biodegradability. ${ }^{159}$ 
An important approach is to synthesize a block copolymer that contains conjugated oligomers and degradable subunits. As model compounds of CPs, conjugated oligomers with welldefined structures have been heavily investigated due to their good electroactivity, enhanced solubility and excellent processability. ${ }^{160}$ Moreover, oligomers of CPs can be consumed by macrophages, and subsequently cleared by kidney. ${ }^{161,162}$ To achieve optimal mechanical, electrical and biological properties and degradation profile for a targeted application, it is desirable to promote architectural diversity (e.g., linear, grafted, star-shaped, hyperbranched, crosslinked). ${ }^{163,164}$ Schmidt's group have synthesized a series of biodegradable and conductive block copolymers composed of degradable ester linkers and conjugated oligomers, including oligopyrroles, oligothiophenes and oligoanilines. ${ }^{165,166}$ However, the electronic conductivity is impeded by the limited availability of dopants and low extent of $\pi$-conjugation along the polymer backbone, thus not suitable for battery applications.

Synthesizing conducting polymer composites or blends with a biodegradable polymer is another important strategy to fabricate biodegradable conductive polymers. These composites/blends are usually prepared by emulsion polymerization of conducting polymer nanoparticles in the synthetic polymer solution, followed by precipitation with organic solvents and a wash with deionized water. ${ }^{167}$ They can be further processed into a membrane by casting onto a plate. The conductivity and biodegradability can be controlled by adjusting the proportions of conducing polymer in the blend/composite. However, CPs nanoparticles at low content are unable to form a conductive network within the biodegradable polymer matrix. Generally, these biodegradable conductive copolymers or composites/blends usually suffer from a low conductivity $\left(10^{-7}-10^{-3} \mathrm{~S} \mathrm{~cm}^{-1}\right)$ and poor electrochemical activity, making them unsuitable for battery applications. ${ }^{168}$

To achieve a high conductivity and electrocatalytic activity while ensuring a large biodegradability, a bilayer structure for combining two components is an option. ${ }^{169} \mathrm{Jia}$ et al. demonstrated a novel air cathode material by chemically depositing a thin continuous PPy layer only onto one side of a silk film (SF-PPy). ${ }^{170}$ This bilayer structure facilitated the enzyme to attack the silk film with cleavage sites available on the opposite side. This film showed a conductivity of $\sim 1.1 \mathrm{~S} \mathrm{~cm}^{-1}$. It degraded in a concentrated buffered protease XIV solution, with a weight loss of $82 \%$ after 15 days (Figure 10a). Degradation of the silk substrate led to fracture and disintegration of SF-PPy film (Figure 10b), thereby offering the possibility of elimination by renal excretion, phagocytosis, and/or endocytosis. The assembled Mg-air bio-battery 
exhibited a discharge capacity of up to $3.79 \mathrm{mAh} \mathrm{cm}^{-2}$ at a current of $10 \mu \mathrm{A} \mathrm{cm}^{-2}$, offering a specific energy density of $\sim 4.70 \mathrm{~mW} \mathrm{~h} \mathrm{~cm}^{-2}$ (Figure 10c).
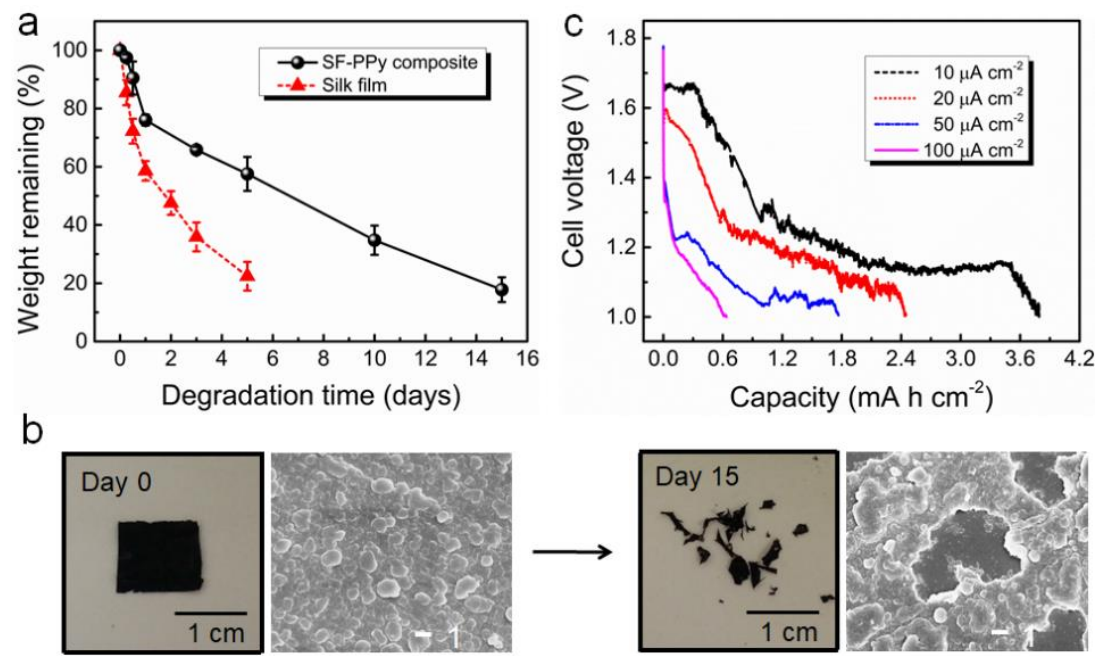

Figure 10 (a) Quantitative changes of silk film and SF-PPy film cultivated in buffered $1.0 \mathrm{mg}$ $\mathrm{mL}^{-1}$ protease XIV solution; (b) Optical and SEM images of SF-PPy film before and after biodegradation; (c) Galvanostatical discharge curves of a Mg-air bio-battery composed of SFPPy film at various current densities in PBS electrolyte; (Reproduced with permission from ref. 170. Copyright 2016, WILEY-VCH Verlag GmbH \& Co. KGaA, Weinheim).

\section{Engineering Solution Processability of Conducting Polymers}

Creating diverse energy storage devices with customized structures and configurations necessitates the continued development of materials processing and fabrication methods. ${ }^{171}$ Advanced fiber-spinning and 3D printing techniques are tools that enable engineering unconventional configurations, such as fiber-shaped or patterned micro-dimensional electrodes. ${ }^{172}$ These electrodes in novel form can be seamlessly integrated into unconventional battery architectures being a structural component of functional devices. ${ }^{173,160}$ Fiber-shaped electrodes have omnidirectional flexibility and can be integrated into smart textiles. ${ }^{174}$ Threedimensional micro-scaled electrodes are essential to achieve miniaturized batteries with high performance. ${ }^{175}$ Beyond that, CPs can also be processed into mechanically robust, freestanding films. This allows for easy fabrication of thin flexible/wearable batteries that can be bent, folded or even stretched while maintaining their functional properties. This type of electrode offer advantages of high energy density and long cycle life by avoiding the drawbacks 
of dead weight/volume of additives and enhanced mechanical stability during charge-discharge cycling. ${ }^{176-178}$

Although CPs are of intrinsic flexibility, they typically lack solution processability due to the rigid conjugated main chain. CPs can be readily tailored by modifying the molecular structure to enable the solution processability. Fabricating hydrophilic CPs nanoparticles is attractive regarding the processing in water-based solvents. Attaching appropriate flexible side chains (substituents) can make CPs soluble in organic solvents, for example, P3HT is soluble in organic solvents such as toluene, chlorobenzene and dichlorobenzene. ${ }^{179}$ A water-soluble selfdoped PANI, poly(2-methoxyaniline-5-sulfonate), was synthesised by chemical and electrochemical polymerization via introducing sulfonic acid groups onto the polymer backbone. ${ }^{180}$ Cao et al. synthesized soluble PANI by using a functionalized protonic acid to protonate PANI. ${ }^{181,182}$ The counterion, dodecylbenzenesulphonic acid (DBSA), can endow processability of PANI at the emeraldine base form with a high conductivity of $10^{2} \mathrm{~S} \mathrm{~cm}^{-1}$.

\section{Spinnable Conducting Polymers Fiber}

Flexible fiber-type batteries are lightweight, easily folded, woven into textiles or even reshaped into other architectures with high efficiency at low cost. ${ }^{173}$ Fiber electrodes can be arranged either helically or in parallel for constructing batteries. Among all fiber spinning methods, wet spinning is the most used to produce CPs fibers owing to its ease of processing (Figure 11a). ${ }^{183}$ CPs dispersed in a solvent are extruded into a coagulation bath in which fibers are solidified. PANI was the first wet-spinning produced fiber, as its emeraldine form was soluble in $\mathrm{N}$ methyl-2-pyrrolidinone (NMP) or N,N'-dimethyl propylene urea (DMPU) to form the spinning solution. ${ }^{184}$ This facile fabrication technique can produce fibers of long length with a large aspect ratio and high alignment. The PANI fiber with a conductivity of $140 \mathrm{~S} \mathrm{~cm}^{-1}$ and a tensile strength in the order of 3-4 GPa have been produced. With a CNT content of $0.25 \mathrm{wt} \%$, it exhibited a discharge capacity of $12.1 \mathrm{mAh} \mathrm{g}^{-1}$ when tested in an ionic liquid electrolyte, ethylmethyl-bis-(trifluoromethane sulfonyl) amide (EMI.TFSA) (Figure 11b,c). ${ }^{185}$ PEDOTPSS fibers can also be fabricated via wet-spinning from an aqueous colloidal suspension with a diameter ranging between $4.6-16 \mu \mathrm{m}$ with a conductivity of $\sim 0.1 \mathrm{~S} \mathrm{~cm}^{-1}{ }^{186}$ 


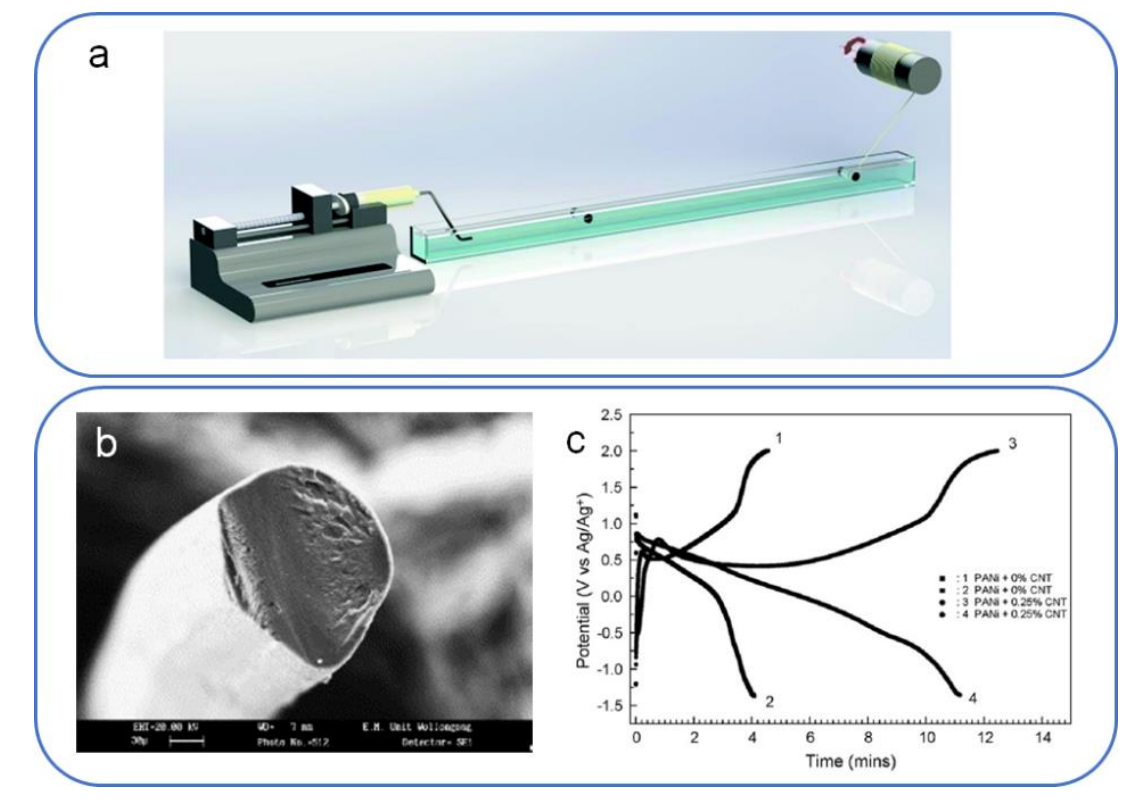

Figure 11 (a) Schematic of a wet spinning process; (Reproduced with permission from ref. 183. Copyright 2016, Royal Society of Chemistry). (b) Scanning electron micrographs of PANI/CNT fiber electrode; (c) Charge and discharge of PANI fiber (1 and 2) and PANI/CNT fiber (3 and 4) in EMI.TFSA; (Reproduced with permission from ref. 185. Copyright 2007, Elsevier Ltd).

Unlike wet spinning producing microfibers, electrospinning is a versatile method to produce polymer fibers at the nano- to submicron scale. ${ }^{187}$ Electrospun nanofibers show unique properties including nanointerface, high surface-to-volume ratio, and large surface area; they are all the factors to improve the performance of energy storage devices. ${ }^{188}$ During the electrospinning processes, polymer solution is extruded from an orifice to form a small droplet in the presence of an electric field and then extruded from the cone, resulting in the formation of micro/nanofiber. Pure PANI nanofibers with diameters of hundreds nanometres were produced via electrospinning without adding non-conductive polymers. ${ }^{189}$ Electrospun PPy/sulfonated-poly(styrene-ethylene-butylenes-styrene) composite nanofibers with a diameter of $300 \mathrm{~nm}$ were prepared. ${ }^{190}$ This material delivered a discharge capacity of $80 \mathrm{mAh}$ $\mathrm{g}^{-1}$ coupled with a Li metal anode, higher than that $48 \mathrm{mAh} \mathrm{g}^{-1}$ from traditional casting fibers.

\section{Printable Conducting Polymer Electrode}

Printable power sources can be fully integrated with printed electronics. Printing is a versatile fabrication method for creating free-form two- and three-dimensional structures. It has emerged as a powerful tool for fabricating micro-dimensional electrodes with pre-designed 
patterns. ${ }^{191}$ Among various printing technologies, screen printing and inkjet printing are preferred because they are amenable to large-scale production. ${ }^{192}$ Screen printing is a simple and environmentally friendly way to produce electronic circuitry and make interconnections, while inkjet printing has emerged as an attractive patterning technique due to its high resolution. ${ }^{193}$ Beyond those, direct ink writing, a 3D printing technology, enables almost infinite possibilities for controllable 3D structural prototyping. ${ }^{194}$ Printing technologies rely heavily on the properties of inks. The key challenge to achieve printable CPs exists in the ink formulations, which should provide appropriate delivery and curing characteristics while preserving high conductivity. Colloidal particles serve as a role equivalent to pigments in an ink solution and are critical for processing CPs.

Nanodispersions of CPs can be formed with the sterically stabilized colloids that consist of an inner core of CPs nanoparticles surrounded by an outer layer of absorbed, insulating stabilizer. ${ }^{195}$ Polyvinyl alcohol, polyvinyl pyrrolidine, and polyethylene oxide are the frequently used stabilizers. Poly(vinyl alcohol-co-acetate) stabilized PPy dispersion has been produced, and the subsequent PPy film on gold layer fabricated by printing has been demonstrated. ${ }^{196}$ Aqueous PANI nanodispersion doped with DBSA with a uniform particle size of $80 \mathrm{~nm}$ is suitable for use as inks, as demonstrated by the high-quality patterns on paper in just $30 \mathrm{~s}$ via inkjet printing. ${ }^{197}$ Colloidal dispersions of CPs can also be prepared in micellar solution via micro-emulsion polymerization, in which particle size is predetermined by the micelle template. PEDOT nanoparticles with a size over a range of 30-100 nm and a conductivity of $50 \mathrm{~S} \mathrm{~cm}^{-1}$ was obtained via such polymerization. ${ }^{198}$ High-resolution 3D PANI structures were fabricated by direct ink writing method, where the processability of PANI/DBSA was achieved by means of a counterion induced thermal doping method. ${ }^{199}$

The use of printed CPs currently has centred on the creation of chemosensors, biosensors, solar cells, and consumer electronics. ${ }^{200,201}$ Flexible patterned supercapacitors composed of PANI or PEDOT electrode have been achieved through screen printing and inkjet printing. ${ }^{202,203}$ Printing techniques normally produce a thin-film electrode, leading to a high gravimetric capacity. Clark et al. firstly demonstrated a flexible zinc-air battery on paper with a screenprinted zinc/carbon/polymer composite anode. ${ }^{204}$ The PEDOT cathode was prepared by inkjet printing oxidant solution in patterns onto paper, followed by vapour phase polymerisation of the monomer. This paper-based battery exhibited a discharge capacity of $0.5 \mathrm{mAh} \mathrm{cm} \mathrm{cm}^{-2}$ with an open-circuit voltage of $1.2 \mathrm{~V}$. An ultra-thin all-polymer battery has been assembled from 
bipolar PEDOT-PSS electrodes (same material in the cathode and anode) on polyethyleneimine (PEI) film via screen printing technology (Figure 12a,b). ${ }^{205}$ The difference in the oxidation level between these two electrodes produced an open circuit voltage of $0.60 \mathrm{~V}$ and displayed a specific capacity of $5.5 \mathrm{mAh} \mathrm{g}^{-1}$ (Figure 12c).
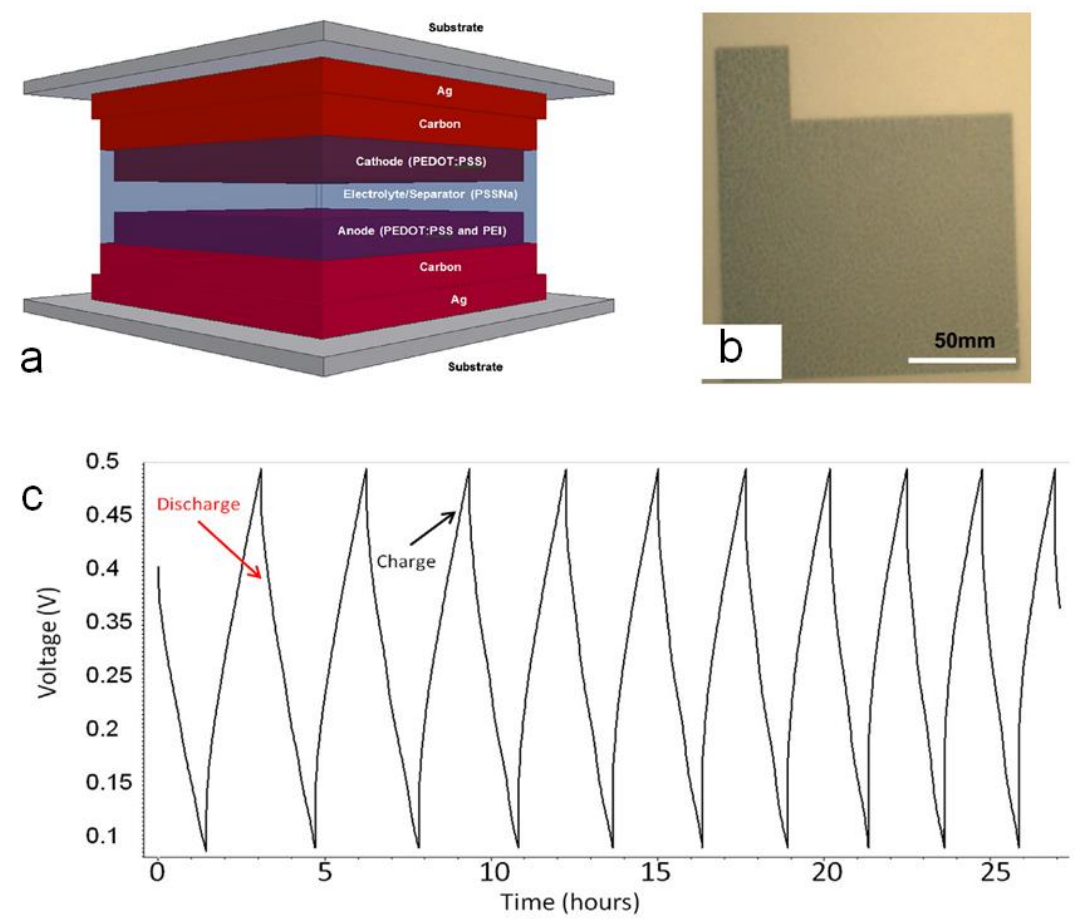

Figure 12 (a) Schematic diagram of a printed polymer battery; (b) Micrographs of PEDOTPEI electrode; (c) Charge and discharge curves of a bipolar polymer battery composed of PEDOT-PSS electrodes at a current of $0.6 \mu \mathrm{A}$; (Reproduced with permission from ref. 205. Copyright 2015, Elsevier Ltd).

\section{Conclusions and Outlook}

Research on energy storage is driven by the huge electronic devices market. CPs are promising energy storage materials due to their sustainability, light weight, ease of processability and tailorable electrochemical properties. Their relatively low specific capacities resulting from the low doping level have not been an obstacle to their development.

Through chemical modification of CP backbone with pendant redox-active groups or inserted as counterion dopants, additional redox active sites are introduced resulting in improved electrochemical performance. The vast toolbox of organic chemistry enables facile chemical engineering of molecular structure. For designing these conducting redox polymers, proper 
selection of redox group and backbone types needs to be considered to achieve a potential match. Redox reactions of pendant groups need to occur within the potential region defined by the CP backbone to ensure that the polymer chain is conductive and electrochemically stable. This is the prerequisite to achieve fast charge transfer, stable redox cycling and simultaneously avoiding charge capacity losses due to inactive (resistive) regions. An appropriate choice of a linker between redox group and backbone is another critically important aspect to preserve the individual redox behavior of active moieties. The bridge connecting pendants and polymer chain has a great impact on the electrochemical properties of substituted materials by modulating the interaction between polymer backbone and redox pendants.

Another critical factor that determines the conductivity and capacity of CPs is precise manipulation of doping. The realisation of stable n-doped CPs with high charge storage determines the development of all-polymer battery when coupled with a p-doped CP. The doping mechanism of inserting metal cations onto the atoms with lone pair electrons $(O, N)$ and unsaturated carbon atoms may offer new opportunities as anodes. In a rechargeable battery, dopants forms a major constituent for the electrolyte. It is highly recommended to choose a proper dopant that shows a high ionic mobility and a good ion-solvent interaction with CPs.

Cycling stability is also an important issue facing the application of organic electrodes in rechargeable batteries. Pristine CPs commonly suffer from poor cycling stability due to the degradation induced by volume changes during the charge/discharge cycling, as well as the inactive structural changes stemmed from the irreversible overoxidation reaction at high voltage. To overcome these problems, two approaches may be applied: the incorporation of immobilised dopants such as large sheet rGO that allows the insertion of small ions for alleviating volume changes; the introduction of electron-rich fused rings into the conjugated backbone to improve the stability of conjugated polymers at high voltages.

Recent research not only focuses on enhancing the battery performance but also shifting towards additional functionalities and unconventional architectures. New functionality, such as biodegradability, could be endowed when incorporating chemically degradable units into the backbone of CPs or forming biopolymer-CP composites/blends. This design could obviate the need to regulate molecular weight as the polymer would be hydrolytically and/or enzymatically degraded in vivo, generating polymer fragments that would be small enough to be renally cleared. The versatility afforded on functionalizing CPs opens the door for more advanced applications in implantable medical devices. 
Developing stable solutions or colloidal dispersions of CPs is crucial for subsequent processing. Solubility of CPs can be controlled by grafting pendant groups to the backbone. CPs electrodes in unconventional configurations hold great promise in the seamless integration of batteries with wearable or implantable electronic devices. Another emerging research trend in the battery industry is miniaturization retaining high performance. The development of micro-scaled energy storage devices is critical to the development of autonomous electronic systems and wireless technologies. Low-cost printing techniques can significantly contribute micro-sized electrodes and batteries based on CPs.

The diversity in molecular structure attainable through synthetic strategies currently available enables precise tuning of CPs that can promote the development of sustainable and versatile energy storage systems. A thorough understanding of the redox processes as well as the structural changes of CPs occurring within a battery system using in situ/operando characterization techniques will provide further information to enable the design and synthesis of new CPs.

\section{Conflicts of interest}

There are no conflicts to declare.

\section{Acknowledgement}

Funding from the Australian Research Council Centre of Excellence Scheme (CE 140100012) is gratefully acknowledged. G.G.W. is grateful to the ARC for support under the Australian Laureate Fellowship scheme FL110100196.

\section{References}

1. Grey, C. P.; Tarascon, J. M., Sustainability and in situ monitoring in battery development. Nat. Mater. 2016, 16, 45-56.

2. Akinyele, D. O.; Rayudu, R. K., Review of energy storage technologies for sustainable power networks. Sustainable Energy Technol. Assess. 2014, 8, 74-91.

3. Xie, J.; Zhang, Q., Recent progress in rechargeable lithium batteries with organic materials as promising electrodes. J. Mater. Chem. A 2016, 4 (19), 7091-7106.

4. Cheng, X.-B.; Zhang, R.; Zhao, C.-Z.; Zhang, Q., Toward Safe Lithium Metal Anode in Rechargeable Batteries: A Review. Chem. Rev. 2017, 117 (15), 10403-10473.

5. Yoshio, M.; Brodd, R. J.; Kozawa, A., Lithium-Ion Batteries: Science and Technologies. Springer New York: 2010. 
6. Larcher, D.; Tarascon, J. M., Towards greener and more sustainable batteries for electrical energy storage. Nat. Chem. 2015, 7 (1), 19-29.

7. $\quad$ Armand, M.; Tarascon, J. M., Building better batteries. Nature 2008, 451 (7179), 652657.

8. Poizot, P.; Dolhem, F., Clean energy new deal for a sustainable world: from non-CO2 generating energy sources to greener electrochemical storage devices. Energy Environ. Sci. 2011, 4 (6), 2003-2019.

9. Tarascon, J.-M., Towards Sustainable and Renewable Systems for Electrochemical Energy Storage. ChemSusChem 2008, 1 (8-9), 777-779.

10. Xie, J.; Zhang, Q., Recent Progress in Multivalent Metal (Mg, Zn, Ca, and Al) and Metal-Ion Rechargeable Batteries with Organic Materials as Promising Electrodes. Small 2019, 15 (15), 1805061.

11. Larcher, D.; Tarascon, J. M., Towards greener and more sustainable batteries for electrical energy storage. Nat. Chem. 2014, 7, 19-29.

12. Gandini, A.; Lacerda, T. M., From monomers to polymers from renewable resources: Recent advances. Prog. Polym. Sci. 2015, 48, 1-39.

13. Zeng, W.; Shu, L.; Li, Q.; Chen, S.; Wang, F.; Tao, X.-M., Fiber-Based Wearable Electronics: A Review of Materials, Fabrication, Devices, and Applications. Adv. Mater. 2014, 26 (31), 5310-5336.

14. Gubbi, J.; Buyya, R.; Marusic, S.; Palaniswami, M., Internet of Things (IoT): A vision, architectural elements, and future directions. Future Gener. Comput. Syst. 2013, 29 (7), 16451660 .

15. Irimia-Vladu, M., "Green" electronics: biodegradable and biocompatible materials and devices for sustainable future. Chem. Soc. Rev. 2014, 43 (2), 588-610.

16. Feig, V. R.; Tran, H.; Bao, Z., Biodegradable Polymeric Materials in Degradable Electronic Devices. ACS Central Sci. 2018, 4 (3), 337-348.

17. Admassie, S.; Ajjan, F. N.; Elfwing, A.; Inganäs, O., Biopolymer hybrid electrodes for scalable electricity storage. Mater. Horizons 2016, 3 (3), 174-185.

18. Zhang, L.; Liu, Z.; Cui, G.; Chen, L., Biomass-derived materials for electrochemical energy storages. Prog. Polym. Sci. 2015, 43, 136-164.

19. Meng, Q.; Cai, K.; Chen, Y.; Chen, L., Research progress on conducting polymer based supercapacitor electrode materials. Nano Energy 2017, 36, 268-285.

20. Posudievsky, O. Y.; Kozarenko, O. A.; Dyadyun, V. S.; Koshechko, V. G.; Pokhodenko, V. D., Electrochemical performance of mechanochemically prepared polyaniline doped with lithium salt. Synth. Met. 2012, 162 (24), 2206-2211.

21. Su, D.; Zhang, J.; Dou, S.; Wang, G., Polypyrrole hollow nanospheres: stable cathode materials for sodium-ion batteries. Chem. Commun. 2015, 51 (89), 16092-16095.

22. Li, S.; Shu, K.; Zhao, C.; Wang, C.; Guo, Z.; Wallace, G.; Liu, H. K., One-Step Synthesis of Graphene/Polypyrrole Nanofiber Composites as Cathode Material for a Biocompatible Zinc/Polymer Battery. ACS Appl. Mater. Interfaces 2014, 6 (19), 16679-16686. 23. Zhao, F.; Li, Y.; Feng, W., Recent Advances in Applying Vulcanization/Inverse Vulcanization Methods to Achieve High-Performance Sulfur-Containing Polymer Cathode Materials for Li-S Batteries. Small Methods 2018, 2 (11), 1800156.

24. Oh, S. H.; Lee, C. W.; Chun, D. H.; Jeon, J. D.; Shim, J.; Shin, K. H.; Yang, J. H., A metal-free and all-organic redox flow battery with polythiophene as the electroactive species. J. Mater. Chem. A 2014, 2 (47), 19994-19998.

25. Rubinson, J. F.; Kayinamura, Y. P., Charge transport in conducting polymers: insights from impedance spectroscopy. Chem. Soc. Rev. 2009, 38 (12), 3339-3347. 
26. Abdelhamid, M. E.; O'Mullane, A. P.; Snook, G. A., Storing energy in plastics: a review on conducting polymers \& their role in electrochemical energy storage. $R S C A d v$. 2015, 5 (15), 11611-11626.

27. Rudge, A.; Davey, J.; Raistrick, I.; Gottesfeld, S.; Ferraris, J. P., Conducting polymers as active materials in electrochemical capacitors. J. Power Sources 1994, 47 (1), 89-107.

28. Goto, F.; Abe, K.; Ikabayashi, K.; Yoshida, T.; Morimoto, H., The polyaniline/lithium battery. J. Power Sources 1987, 20 (3), 243-248.

29. Matsunaga, T.; Daifuku, H.; Nakajima, T.; Kawagoe, T., Development of polyanilinelithium secondary battery. Polym. Adv. Technol. 1990, 1 (1), 33-39.

30. Jalili, R.; Razal, J. M.; Innis, P. C.; Wallace, G. G., One-Step Wet-Spinning Process of Poly(3,4-ethylenedioxythiophene):Poly(styrenesulfonate) Fibers and the Origin of Higher Electrical Conductivity. Adv. Funct. Mater. 2011, 21 (17), 3363-3370.

31. Kim, J.; Kim, J. H.; Ariga, K., Redox-Active Polymers for Energy Storage Nanoarchitectonics. Joule 2017, 1 (4), 739-768.

32. Novák, P.; Müller, K.; Santhanam, K. S. V.; Haas, O., Electrochemically Active Polymers for Rechargeable Batteries. Chem. Rev. 1997, 97 (1), 207-282.

33. Mike, J. F.; Lutkenhaus, J. L., Electrochemically Active Polymers for Electrochemical Energy Storage: Opportunities and Challenges. ACS Macro Lett. 2013, 2 (9), 839-844.

34. Xie, J.; Gu, P.; Zhang, Q., Nanostructured Conjugated Polymers: Toward HighPerformance Organic Electrodes for Rechargeable Batteries. ACS Energy Lett. 2017, 2 (9), 1985-1996.

35. Lu, Y.; Zhang, Q.; Li, L.; Niu, Z.; Chen, J., Design Strategies toward Enhancing the Performance of Organic Electrode Materials in Metal-Ion Batteries. Chem 2018, 4 (12), 27862813.

36. Heeger, A. J., Semiconducting and Metallic Polymers: The Fourth Generation of Polymeric Materials. J. Phys. Chem. B 2001, 105 (36), 8475-8491.

37. Heeger, A. J.; Kivelson, S.; Schrieffer, J. R.; Su, W. P., Solitons in conducting polymers. Rev. Modern Phys. 1988, 60 (3), 781-850.

38. Heeger, A. J., Semiconducting and Metallic Polymers: The Fourth Generation of Polymeric Materials (Nobel Lecture). Angew. Chem. Int. Ed. 2001, 40 (14), 2591-2611.

39. Ghosh, S.; Maiyalagan, T.; Basu, R. N., Nanostructured conducting polymers for energy applications: towards a sustainable platform. Nanoscale 2016, 8 (13), 6921-6947.

40. Song, Z.; Zhou, H., Towards sustainable and versatile energy storage devices: an overview of organic electrode materials. Energy Environ. Sci. 2013, 6 (8), 2280-2301.

41. Kim, H.; Kim, H.; Ding, Z.; Lee, M. H.; Lim, K.; Yoon, G.; Kang, K., Recent Progress in Electrode Materials for Sodium-Ion Batteries. Adv. Energy Mater. 2016, 6 (19), 1600943.

42. Slater, M. D.; Kim, D.; Lee, E.; Johnson, C. S., Sodium-Ion Batteries. Adv. Funct. Mater. 2013, 23 (8), 947-958.

43. Qian, J.; Wu, X.; Cao, Y.; Ai, X.; Yang, H., High Capacity and Rate Capability of Amorphous Phosphorus for Sodium Ion Batteries. Angew. Chem. Int. Ed. 2013, 125 (17), 47314734.

44. Simotwo, S. K.; Kalra, V., Polyaniline-based electrodes: recent application in supercapacitors and next generation rechargeable batteries. Curr. Opin. Chem. Eng. 2016, 13, 150-160.

45. Heinze, J.; Frontana-Uribe, B. A.; Ludwigs, S., Electrochemistry of Conducting Polymers-Persistent Models and New Concepts. Chem. Rev. 2010, 110 (8), 4724-4771.

46. Mike, J. F.; Lutkenhaus, J. L., Recent advances in conjugated polymer energy storage. J. Polym. Sci. B 2013, 51 (7), 468-480. 
47. Cui, Q.; Bazan, G. C., Narrow Band Gap Conjugated Polyelectrolytes. Acc. Chem. Res. 2018, 51 (1), 202-211.

48. Muench, S.; Wild, A.; Friebe, C.; Häupler, B.; Janoschka, T.; Schubert, U. S., Polymer-Based Organic Batteries. Chem. Rev. 2016, 116 (16), 9438-9484.

49. Kim, J.; Lee, J.; You, J.; Park, M.-S.; Hossain, M. S. A.; Yamauchi, Y.; Kim, J. H., Conductive polymers for next-generation energy storage systems: recent progress and new functions. Mater. Horizons 2016, 3 (6), 517-535.

50. Gracia, R.; Mecerreyes, D., Polymers with redox properties: materials for batteries, biosensors and more. Polym. Chem.2013, 4 (7), 2206-2214.

51. Casado, N.; Hernández, G.; Sardon, H.; Mecerreyes, D., Current trends in redox polymers for energy and medicine. Prog. Polym. Sci. 2016, 52, 107-135.

52. Vonlanthen, D.; Lazarev, P.; See, K. A.; Wudl, F.; Heeger, A. J., A Stable PolyanilineBenzoquinone-Hydroquinone Supercapacitor. Adv. Mater. 2014, 26 (30), 5095-5100.

53. Yue, B.; Wang, C.; Wagner, P.; Yang, Y.; Ding, X.; Officer, D. L.; Wallace, G. G., Electrodeposition of pyrrole and 3-(4-tert-butylphenyl)thiophene copolymer for supercapacitor applications. Synth. Met. 2012, 162 (24), 2216-2221.

54. Park, K. S.; Schougaard, S. B.; Goodenough, J. B., Conducting-Polymer/Iron-RedoxCouple Composite Cathodes for Lithium Secondary Batteries. Adv. Mater. 2007, 19 (6), 848851.

55. Sen, S.; Saraidaridis, J.; Kim, S. Y.; Palmore, G. T. R., Viologens as Charge Carriers in a Polymer-Based Battery Anode. ACS Appl. Mater. Interfaces 2013, 5 (16), 7825-7830.

56. Nakahara, K.; Oyaizu, K.; Nishide, H., Organic Radical Battery Approaching Practical Use. Chem. Lett. 2011, 40 (3), 222-227.

57. Xu, L.; Yang, F.; Su, C.; Ji, L.; Zhang, C., Synthesis and properties of novel TEMPOcontained polypyrrole derivatives as the cathode material of organic radical battery. Electrochim. Acta 2014, 130, 148-155.

58. Karlsson, C.; Huang, H.; Strømme, M.; Gogoll, A.; Sjödin, M., Quinone pendant group kinetics in poly(pyrrol-3-ylhydroquinone). J. Electroanal. Chem. 2014, 735, 95-98.

59. Emanuelsson, R.; Huang, H.; Gogoll, A.; Strømme, M.; Sjödin, M., Enthalpic versus Entropic Contribution to the Quinone Formal Potential in a Polypyrrole-Based Conducting Redox Polymer. J. Phys. Chem C 2016, 120 (38), 21178-21183.

60. Häupler, B.; Wild, A.; Schubert, U. S., Carbonyls: Powerful Organic Materials for Secondary Batteries. Adv. Energy Mater. 2015, 5 (11), 1402034.

61. Amaike, M.; Iihama, T., Chemical polymerization of pyrrole with disulfide structure and the application to lithium secondary batteries. Synth. Met. 2006, 156 (2), 239-243.

62. Shen, Y. F.; Yuan, D. D.; Ai, X. P.; Yang, H. X.; Zhou, M., Poly(diphenylaminesulfonic acid sodium) as a cation-exchanging organic cathode for sodium batteries. Electrochem. Commun. 2014, 49, 5-8.

63. Zhu, L.; Shen, Y.; Sun, M.; Qian, J.; Cao, Y.; Ai, X.; Yang, H., Self-doped polypyrrole with ionizable sodium sulfonate as a renewable cathode material for sodium ion batteries. Chem. Commun. 2013, 49 (97), 11370-11372.

64. Häringer, D.; Novák, P.; Haas, O.; Piro, B.; Pham, M. C., Poly(5-amino-1,4naphthoquinone), a Novel Lithium-Inserting Electroactive Polymer with High Specific Charge. J. Electrochem. Soc. 1999, 146 (7), 2393-2396.

65. Pham, M. C.; Piro, B.; Bazzaoui, E. A.; Hedayatullah, M.; Lacroix, J. C.; Novak, P.; Haas, O., Anodic oxidation of 5-amino-1,4-naphthoquinone (ANQ) and synthesis of a conducting polymer (PANQ). Synth. Met. 1998, 92 (3), 197-205.

66. Zhao, L.; Wang, W.; Wang, A.; Yuan, K.; Chen, S.; Yang, Y., A novel polyquinone cathode material for rechargeable lithium batteries. J. Power Sources 2013, 233, 23-27. 
67. Shen, Y. F.; Yuan, D. D.; Ai, X. P.; Yang, H. X.; Zhou, M., High capacity and cycling stability of poly(diaminoanthraquinone) as an organic cathode for rechargeable lithium batteries. J. Polym. Sci. B 2015, 53 (4), 235-238.

68. Vlad, A.; Arnould, K.; Ernould, B.; Sieuw, L.; Rolland, J.; Gohy, J.-F., Exploring the potential of polymer battery cathodes with electrically conductive molecular backbone. $J$. Mater. Chem. A 2015, 3 (21), 11189-11193.

69. Naoi, K.; Kawase, K. i.; Inoue, Y., A New Energy Storage Material: Organosulfur Compounds Based on Multiple Sulfur-Sulfur Bonds. J. Electrochem. Soc. 1997, 144 (6), L170L172.

70. Naoi, K.; Kawase, K. i.; Mori, M.; Komiyama, M., Electrochemistry of Poly(2,2'dithiodianiline): A New Class of High Energy Conducting Polymer Interconnected with S-S Bonds. J. Electrochem. Soc. 1997, 144 (6), L173-L175.

71. Su, Y.-Z.; Niu, Y.-P.; Xiao, Y.-Z.; Xiao, M.; Liang, Z.-X.; Gong, K.-C., Novel conducting polymer poly[bis(phenylamino)disulfide]: Synthesis, characterization, and properties. J. Polym. Sci. A 2004, 42 (10), 2329-2339.

72. Wang, G.; Yang, X.; Sun, Y.; Bao, H.; Li, X., Aniline-Based Disulfide/Aniline Copolymers as a High Energy-Storage Material. Macromol. Chem. Phy. 2009, 210 (24), 21182124.

73. Su, Y.-Z.; Dong, W.; Zhang, J.-H.; Song, J.-H.; Zhang, Y.-H.; Gong, K.-C., Poly[bis(2-aminophenyloxy)disulfide]: A polyaniline derivative containing disulfide bonds as a cathode material for lithium battery. Polymer 2007, 48 (1), 165-173.

74. Li, J.; Zhan, H.; Zhou, L.; Deng, S.; Li, Z.; Zhou, Y., Aniline-based polyorganodisulfide redox system of high energy for secondary lithium batteries. Electrochem. Commun. 2004, 6 (6), 515-519.

75. Oyaizu, K.; Tatsuhira, H.; Nishide, H., Facile charge transport and storage by a TEMPO-populated redox mediating polymer integrated with polyaniline as electrical conducting path. Polym. J. 2014, 47, 212-219.

76. Su, C.; Ji, L.; Xu, L.; Zhu, X.; He, H.; Lv, Y.; Ouyang, M.; Zhang, C., A novel ferrocene-containing aniline copolymer: its synthesis and electrochemical performance. $R S C$ $A d v .2015,5$ (18), 14053-14060.

77. Chen, C.; Hong, X.; Chen, A.; Xu, T.; Lu, L.; Lin, S.; Gao, Y., Electrochemical properties of poly(aniline-co-N-methylthionine) for zinc-conducting polymer rechargeable batteries. Electrochim. Acta 2016, 190, 240-247.

78. Zhou, M.; Li, W.; Gu, T.; Wang, K.; Cheng, S.; Jiang, K., A sulfonated polyaniline with high density and high rate Na-storage performances as a flexible organic cathode for sodium ion batteries. Chem. Commun. 2015, 51 (76), 14354-14356.

79. Zhao, R.; Zhu, L.; Cao, Y.; Ai, X.; Yang, H. X., An aniline-nitroaniline copolymer as a high capacity cathode for Na-ion batteries. Electrochem. Commun. 2012, 21, 36-38.

80. Zhu, X.; Zhao, R.; Deng, W.; Ai, X.; Yang, H.; Cao, Y., An All-solid-state and Allorganic Sodium-ion Battery based on Redox-active Polymers and Plastic Crystal Electrolyte. Electrochim. Acta 2015, 178, 55-59.

81. Snook, G. A.; Kao, P.; Best, A. S., Conducting-polymer-based supercapacitor devices and electrodes. J. Power Sources 2011, 196 (1), 1-12.

82. Sato, M.-a.; Tanaka, S.; Kaeriyama, K., Electrochemical preparation of highly conducting polythiophene films. J. Chem. Soc. Chem. Commun. 1985, (11), 713-714.

83. Sarker, H.; Gofer, Y.; Killian, J. G.; Poehler, T. O.; Searson, P. C., Synthesis and characterization of a series of fluorine-substituted phenylene-thienyl polymers for battery applications. Synth. Met. 1998, 97 (1), 1-6. 
84. Sarker, H.; Gofer, Y.; Killian, J. G.; Poehler, T. O.; Searson, P. C., Synthesis and characterization of fluoro-substituted polyphenylthiophenes for charge storage applications. Synth. Met. 1997, 88 (3), 179-185.

85. Gofer, Y.; Killian, J. G.; Sarker, H.; Poehler, T. O.; Searson, P. C., The electrochemistry of fluorine-substituted polyphenylthiophenes for charge storage applications. J. Electroanal. Chem. 1998, 443 (1), 103-115.

86. Levi, M. D.; Fisyuk, A. S.; Demadrille, R.; Markevich, E.; Gofer, Y.; Aurbach, D.; Pron, A., Unusually high stability of a poly(alkylquaterthiophene-alt-oxadiazole) conjugated copolymer in its n and p-doped states. Chem. Commun. 2006, (31), 3299-3301.

87. Liang, Y.; Chen, Z.; Jing, Y.; Rong, Y.; Facchetti, A.; Yao, Y., Heavily n-Dopable $\pi$-Conjugated Redox Polymers with Ultrafast Energy Storage Capability. J. Am. Chem. Soc. 2015, 137 (15), 4956-4959.

88. Yang, L.; Huang, X.; Gogoll, A.; Strømme, M.; Sjödin, M., Conducting Redox Polymer Based Anode Materials for High Power Electrical Energy Storage. Electrochim. Acta 2016, 204, 270-275.

89. Lutkenhaus, J., A radical advance for conducting polymers. Science 2018, 359 (6382), 1334-1335.

90. Zhang, W.; Feng, P.; Chen, J.; Sun, Z.; Zhao, B., Electrically conductive hydrogels for flexible energy storage systems. Prog. Polym. Sci. 2019, 88, 220-240.

91. Li, F.; Gore, D. N.; Wang, S.; Lutkenhaus, J. L., Unusual Internal Electron Transfer in Conjugated Radical Polymers. Angew. Chem. Int. Ed. 2017, 56 (33), 9856-9859.

92. Chang, A.; Wu, Q.; Du, X.; Chen, S.; Shen, J.; Song, Q.; Xie, J.; Wu, W., Immobilization of sulfur in microgels for lithium-sulfur battery. Chem. Commun. 2016, 52 (24), 4525-4528.

93. Zeng, S.; Li, L.; Xie, L.; Zhao, D.; Wang, N.; Chen, S., Conducting Polymers Crosslinked with Sulfur as Cathode Materials for High-Rate, Ultralong-Life Lithium-Sulfur Batteries. ChemSusChem 2017, 10 (17), 3378-3386.

94. Oschmann, B.; Park, J.; Kim, C.; Char, K.; Sung, Y.-E.; Zentel, R., Copolymerization of Polythiophene and Sulfur To Improve the Electrochemical Performance in Lithium-Sulfur Batteries. Chem. Mater. 2015, 27 (20), 7011-7017.

95. Tsutsumi, H.; Higashiyama, H.; Onimura, K.; Oishi, T., Preparation of poly(Nmethylpyrrole) modified with pentathiepin rings and its application to positive active material for lithium secondary. J. Power Sources 2005, 146 (1), 345-348.

96 Yuan, T.; Ruan, J.; Zhang, W.; Tan, Z.; Yang, J.; Ma, Z.-F.; Zheng, S., Flexible Overoxidized Polypyrrole Films with Orderly Structure as High-Performance Anodes for Liand Na-Ion Batteries. ACS Appl. Mater. Interfaces 2016, 8 (51), 35114-35122.

97. Zhang, J.; Shan, D.; Mu, S., A rechargeable Zn- poly(aniline-co-m-aminophenol) battery. J. Power Sources 2006, 161 (1), 685-691.

98. Tang, J.; Song, Z.-P.; Shan, N.; Zhan, L.-Z.; Zhang, J.-Y.; Zhan, H.; Zhou, Y.-H.; Zhan, C.-M., Poly[3,4-(ethylenedithio)thiophene]: High specific capacity cathode active material for lithium rechargeable batteries. J. Power Sources 2008, 185 (2), 1434-1438.

99. Tang, J.; Kong, L.; Zhang, J.; Zhan, L.; Zhan, H.; Zhou, Y.; Zhan, C., Solvent-free, oxidatively prepared polythiophene: High specific capacity as a cathode active material for lithium batteries. React. Funct. Polym. 2008, 68 (9), 1408-1413.

100. Aydın, M.; Esat, B.; Kılıç, Ç.; Köse, M. E.; Ata, A.; Yılmaz, F., A polythiophene derivative bearing TEMPO as a cathode material for rechargeable batteries. Eur. Polym. J. 2011, 47 (12), 2283-2294.

101. Torres-Gómez, G.; Skaarup, S.; West, K.; Gomez-Romero, P., Energy Storage in Hybrid Organic-Inorganic Materials Hexacyanoferrate-Doped Polypyrrole as Cathode in Reversible Lithium Cells. J. Electrochem. Soc. 2000, 147 (7), 2513-2516. 
102. Zhou, M.; Qian, J.; Ai, X.; Yang, H., Redox-Active Fe(CN)64--Doped Conducting Polymers with Greatly Enhanced Capacity as Cathode Materials for Li-Ion Batteries. Adv. Mater. 2011, 23 (42), 4913-4917.

103. Zhou, M.; Zhu, L.; Cao, Y.; Zhao, R.; Qian, J.; Ai, X.; Yang, H., Fe(CN)6-4-doped polypyrrole: a high-capacity and high-rate cathode material for sodium-ion batteries. RSC Adv. 2012, 2 (13), 5495-5498.

104. Deng, W. W.; Shen, Y. F.; Liang, X. M.; Feng, J. W.; Yang, H. X., Redox-active organics/polypyrrole composite as a cycle-stable cathode for Li ion batteries. Electrochim. Acta 2014, 147, 426-431.

105. Zhou, M.; Xiong, Y.; Cao, Y.; Ai, X.; Yang, H., Electroactive organic anion-doped polypyrrole as a low cost and renewable cathode for sodium-ion batteries. J. Polym. Sci. B 2013, 51 (2), 114-118.

106. Masdarolomoor, F.; Innis, P. C.; Ashraf, S.; Kaner, R. B.; Wallace, G. G., Nanocomposites of Polyaniline/Poly(2-methoxyaniline-5-sulfonic acid). Macromol. Rapid Commun. 2006, 27 (23), 1995-2000.

107. Yang, Y.; Wang, C.; Ashraf, S.; Wallace, G. G., Polypyrrole doped with redox-active poly(2-methoxyaniline-5-sulfonic acid) for lithium secondary batteries. $R S C A d v$. 2013, 3 (16), 5447-5452.

108. Yoneyama, H.; Ii, Y.; Kuwabata, S., Charge-discharge Characteristics of Polypyrrole Films Containing Incorporated Anthraquinone-1-Sulfonate. J. Electrochem. Soc. 1992, 139 (1), 28-32.

109. Yang, Y.; He, K.; Yan, P.; Wang, D.; Wu, X.; Zhao, X.; Huang, Z.; Zhang, C.; He, D., Enhanced Capacity of Polypyrrole/Anthraquinone Sulfonate/Graphene Composite as Cathode in Lithium Batteries. Electrochim. Acta 2014, 138, 481-485.

110. Milczarek, G.; Inganäs, O., Renewable Cathode Materials from Biopolymer/Conjugated Polymer Interpenetrating Networks. Science 2012, 335 (6075), 14681471.

111. Yamamoto, K.; Yamada, M.; Nishiumi, T., Doping reaction of redox-active dopants into polyaniline. Polym. Adv. Technol. 2000, 11 (8-12), 710-715.

112. Wan, F.; Zhang, L.; Wang, X.; Bi, S.; Niu, Z.; Chen, J., An Aqueous Rechargeable Zinc-Organic Battery with Hybrid Mechanism. Adv. Funct. Mater. 2018, 28 (45), 1804975.

113. Shi, H. Y.; Ye, Y. J.; Liu, K.; Song, Y.; Sun, X., A Long-Cycle-Life Self-Doped Polyaniline Cathode for Rechargeable Aqueous Zinc Batteries. Angew. Chem. Int. Ed. 2018, 57 (50), 16359-16363.

114. Suga, T.; Sugita, S.; Ohshiro, H.; Oyaizu, K.; Nishide, H., p- and n-Type Bipolar Redox-Active Radical Polymer: Toward Totally Organic Polymer-Based Rechargeable Devices with Variable Configuration. Adv. Mater. 2011, 23 (6), 751-754.

115. Wang, G.; Zhang, L.; Zhang, J., A review of electrode materials for electrochemical supercapacitors. Chem. Soc. Rev. 2012, 41 (2), 797-828.

116. Gofer, Y.; Sarker, H.; Killian, J. G.; Poehler, T. O.; Searson, P. C., An all-polymer charge storage device. Appl. Phys. Lett. 1997, 71 (11), 1582-1584.

117. Robitaille, A.; Perea, A.; Bélanger, D.; Leclerc, M., Poly(5-alkyl-thieno[3,4-c]pyrrole4,6-dione): a study of $\pi$-conjugated redox polymers as anode materials in lithium-ion batteries. J. Mater. Chem. A 2017, 5 (34), 18088-18094.

118. Jiménez, P.; Levillain, E.; Alévêque, O.; Guyomard, D.; Lestriez, B.; Gaubicher, J., Lithium n-Doped Polyaniline as a High-Performance Electroactive Material for Rechargeable Batteries. Angew. Chem. Int. Ed. 2017, 56 (6), 1553-1556.

119. Baker, C. O.; Huang, X.; Nelson, W.; Kaner, R. B., Polyaniline nanofibers: broadening applications for conducting polymers. Chem. Soc. Rev. 2017, 46 (5), 1510-1525. 
120. Yamaguchi, I.; Nagano, T.; Tuan, L. V., NaH-assisted n-doping of polyanilines with dopant cation trapping sites and their stability of n-doping state against air. Polymer 2015, 73, $79-85$.

121. Zhang, S.; Huang, W.; Hu, P.; Huang, C.; Shang, C.; Zhang, C.; Yang, R.; Cui, G., Conjugated microporous polymers with excellent electrochemical performance for lithium and sodium storage. J. Mater. Chem. A 2015, 3 (5), 1896-1901.

122. Killian, J. G.; Coffey, B. M.; Gao, F.; Poehler, T. O.; Searson, P. C., Polypyrrole Composite Electrodes in an All-Polymer Battery System. J. Electrochem. Soc. 1996, 143 (3), 936-942.

123. Song, H. K.; Palmore, G. T. R., Redox-Active Polypyrrole: Toward Polymer-Based Batteries. Adv. Mater. 2006, 18 (13), 1764-1768.

124. Sultana, I.; Rahman, M. M.; Wang, J.; Wang, C.; Wallace, G. G.; Liu, H.-K., Allpolymer battery system based on polypyrrole (PPy)/para (toluene sulfonic acid) (pTS) and polypyrrole (PPy)/indigo carmine (IC) free standing films. Electrochim. Acta 2012, 83, 209215.

125. Aradilla, D.; Estrany, F.; Casellas, F.; Iribarren, J. I.; Alemán, C., All-polythiophene rechargeable batteries. Organ. Electron. 2014, 15 (1), 40-46.

126. Winther-Jensen, B.; Winther-Jensen, O.; Forsyth, M.; MacFarlane, D. R., High Rates of Oxygen Reduction over a Vapor Phase-Polymerized PEDOT Electrode. Science 2008, 321 (5889), 671-674.

127. Xuan, Y.; Sandberg, M.; Berggren, M.; Crispin, X., An all-polymer-air PEDOT battery. Organ. Electron. 2012, 13 (4), 632-637.

128. Reyes-Reyes, M.; López-Sandoval, R., Optimizing the oxidation level of PEDOT anode in air-PEDOT battery. Organ. Electron. 2018, 52, 364-370.

129. Emanuelsson, R.; Sterby, M.; Strømme, M.; Sjödin, M., An All-Organic Proton Battery. J. Am. Chem. Soc. 2017, 139 (13), 4828-4834.

130. Sterby, M.; Emanuelsson, R.; Huang, X.; Gogoll, A.; Strømme, M.; Sjödin, M., Characterization of PEDOT-Quinone Conducting Redox Polymers for Water Based Secondary Batteries. Electrochim. Acta 2017, 235, 356-364.

131. Wang, C. Y.; Ballantyne, A. M.; Hall, S. B.; Too, C. O.; Officer, D. L.; Wallace, G. G., Functionalized polythiophene-coated textile: A new anode material for a flexible battery. J. Power Sources 2006, 156 (2), 610-614.

132. Wang, C. Y.; Tsekouras, G.; Wagner, P.; Gambhir, S.; Too, C. O.; Officer, D.; Wallace, G. G., Functionalised polyterthiophenes as anode materials in polymer/polymer batteries. Synth. Met. 2010, 160 (1), 76-82.

133. Southcott, M.; MacVittie, K.; Halámek, J.; Halámková, L.; Jemison, W. D.; Lobel, R.; Katz, E., A pacemaker powered by an implantable biofuel cell operating under conditions mimicking the human blood circulatory system - battery not included. Phys. Chem. Chem. Phys. 2013, 15 (17), 6278-6283.

134. Feiner, R.; Dvir, T., Tissue-electronics interfaces: from implantable devices to engineered tissues. Nat. Rev. Mater. 2017, 3, 17076.

135. Wang, S.; Oh, J. Y.; Xu, J.; Tran, H.; Bao, Z., Skin-Inspired Electronics: An Emerging Paradigm. Acc. Chem. Res. 2018, 51 (5), 1033-1045.

136. Bock, D. C.; Marschilok, A. C.; Takeuchi, K. J.; Takeuchi, E. S., Batteries used to power implantable biomedical devices. Electrochim. Acta 2012, 84, 155-164.

137. Bettinger, C. J., Materials Advances for Next-Generation Ingestible Electronic Medical Devices. Trends Biotechnol. 2015, 33 (10), 575-585.

138. Tseung, A. C. C.; King, W. J.; Wan, B. Y. C., An encapsulated, implantable metaloxygen cell as a long-term power source for medical and biological applications. Med. Biol. Eng. Comput. 1971, 9 (3), 175-184. 
139. Zheng, Y. F.; Gu, X. N.; Witte, F., Biodegradable metals. Mater. Sci. Eng. R Rep. 2014, 77, 1-34.

140. Cui, Y.; Wen, Z.; Liang, X.; Lu, Y.; Jin, J.; Wu, M.; Wu, X., A tubular polypyrrole based air electrode with improved $\mathrm{O} 2$ diffusivity for Li-O2 batteries. Energy Environ. Sci. 2012, 5 (7), 7893-7897.

141. Singh, S. K.; Crispin, X.; Zozoulenko, I. V., Oxygen Reduction Reaction in Conducting Polymer PEDOT: Density Functional Theory Study. J. Phys. Chem. C 2017, 121 (22), 12270-12277.

142. Khomenko, V.; Frackowiak, E.; Béguin, F., Determination of the specific capacitance of conducting polymer/nanotubes composite electrodes using different cell configurations. Electrochim. Acta 2005, 50 (12), 2499-2506.

143. Wu, A.; Venancio, E. C.; MacDiarmid, A. G., Polyaniline and polypyrrole oxygen reversible electrodes. Synth. Met. 2007, 157 (6), 303-310.

144. Mitraka, E.; Jafari, M. J.; Vagin, M.; Liu, X.; Fahlman, M.; Ederth, T.; Berggren, M.; Jonsson, M. P.; Crispin, X., Oxygen-induced doping on reduced PEDOT. J. Mater. Chem. A 2017, 5 (9), 4404-4412.

145. Hardy, J. G.; Lee, J. Y.; Schmidt, C. E., Biomimetic conducting polymer-based tissue scaffolds. Curr. Opin. Biotechnol. 2013, 24 (5), 847-854.

146. Balint, R.; Cassidy, N. J.; Cartmell, S. H., Conductive polymers: Towards a smart biomaterial for tissue engineering. Acta Biomater. 2014, 10 (6), 2341-2353.

147. Bendrea, A.-D.; Cianga, L.; Cianga, I., Review paper: Progress in the Field of Conducting Polymers for Tissue Engineering Applications. J. Biomater. Appl. 2011, 26 (1), 384.

148. Qazi, T. H.; Rai, R.; Boccaccini, A. R., Tissue engineering of electrically responsive tissues using polyaniline based polymers: A review. Biomaterials 2014, 35 (33), 9068-9086.

149. Guimard, N. K.; Gomez, N.; Schmidt, C. E., Conducting polymers in biomedical engineering. Prog. Polym. Sci. 2007, 32 (8), 876-921.

150. Molino, P. J.; Zhang, B.; Wallace, G. G.; Hanks, T. W., Surface modification of polypyrrole/biopolymer composites for controlled protein and cellular adhesion. Biofouling 2013, 29 (10), 1155-1167.

151. Stauffer, W. R.; Cui, X. T., Polypyrrole doped with 2 peptide sequences from laminin. Biomaterials 2006, 27 (11), 2405-2413.

152. Kong, Y.; Wang, C.; Yang, Y.; Too, C. O.; Wallace, G. G., A battery composed of a polypyrrole cathode and a magnesium alloy anode-Toward a bioelectric battery. Synth. Met. 2012, 162 (7), 584-589.

153. Yang, Y.; Wang, C.; Zhang, C.; Wang, D.; He, D.; Wallace, G. G., A novel codoping approach for enhancing the performance of polypyrrole cathode in a bioelectric battery. Carbon 2014, 80, 691-697.

154. Yu, C.; Wang, C.; Liu, X.; Jia, X.; Naficy, S.; Shu, K.; Forsyth, M.; Wallace, G. G., A Cytocompatible Robust Hybrid Conducting Polymer Hydrogel for Use in a Magnesium Battery. Adv. Mater. 2016, 28 (42), 9349-9355.

155. Yin, L.; Huang, X.; Xu, H.; Zhang, Y.; Lam, J.; Cheng, J.; Rogers, J. A., Materials, Designs, and Operational Characteristics for Fully Biodegradable Primary Batteries. Adv. Mater. 2014, 26 (23), 3879-3884.

156. Huang, X.; Wang, D.; Yuan, Z.; Xie, W.; Wu, Y.; Li, R.; Zhao, Y.; Luo, D.; Cen, L.; Chen, B.; Wu, H.; Xu, H.; Sheng, X.; Zhang, M.; Zhao, L.; Yin, L., A Fully Biodegradable Battery for Self-Powered Transient Implants. Small 2018, 14 (28), 1800994.

157. Tan, M. J.; Owh, C.; Chee, P. L.; Kyaw, A. K. K.; Kai, D.; Loh, X. J., Biodegradable electronics: cornerstone for sustainable electronics and transient applications. J. Mater. Chem. C 2016, 4 (24), 5531-5558. 
158. Jia, X.; Wang, C.; Ranganathan, V.; Napier, B.; Yu, C.; Chao, Y.; Forsyth, M.; Omenetto, F. G.; MacFarlane, D. R.; Wallace, G. G., A Biodegradable Thin-Film Magnesium Primary Battery Using Silk Fibroin-Ionic Liquid Polymer Electrolyte. ACS Energy Lett. 2017, 2 (4), 831-836.

159. Zhu, H.; Luo, W.; Ciesielski, P. N.; Fang, Z.; Zhu, J. Y.; Henriksson, G.; Himmel, M. E.; Hu, L., Wood-Derived Materials for Green Electronics, Biological Devices, and Energy Applications. Chem. Rev. 2016, 116 (16), 9305-9374.

160. Guo, B.; Glavas, L.; Albertsson, A.-C., Biodegradable and electrically conducting polymers for biomedical applications. Prog. Polym. Sci. 2013, 38 (9), 1263-1286.

161. Ding, Y.; Tang, Y.; Zhu, W.; Xie, Y., Fluorescent and colorimetric ion probes based on conjugated oligopyrroles. Chem. Soc. Rev. 2015, 44 (5), 1101-1112.

162. Nasongkla, N.; Chen, B.; Macaraeg, N.; Fox, M. E.; Fréchet, J. M. J.; Szoka, F. C., Dependence of Pharmacokinetics and Biodistribution on Polymer Architecture: Effect of Cyclic versus Linear Polymers. J. Am. Chem. Soc. 2009, 131 (11), 3842-3843.

163. Guo, B.; Ma, P. X., Synthetic biodegradable functional polymers for tissue engineering: a brief review. Sci. China Chem. 2014, 57 (4), 490-500.

164. Guo, B.; Finne-Wistrand, A.; Albertsson, A.-C., Facile Synthesis of Degradable and Electrically Conductive Polysaccharide Hydrogels. Biomacromolecules 2011, 12 (7), 26012609.

165. Hardy, J. G.; Mouser, D. J.; Arroyo-Currás, N.; Geissler, S.; Chow, J. K.; Nguy, L.; Kim, J. M.; Schmidt, C. E., Biodegradable electroactive polymers for electrochemicallytriggered drug delivery. J. Mater. Chem. B 2014, 2 (39), 6809-6822.

166. Guimard, N. K. E.; Sessler, J. L.; Schmidt, C. E., Toward a Biocompatible and Biodegradable Copolymer Incorporating Electroactive Oligothiophene Units. Macromolecules 2009, 42 (2), 502-511.

167. Kenry; Liu, B., Recent Advances in Biodegradable Conducting Polymers and Their Biomedical Applications. Biomacromolecules 2018, 19 (6), 1783-1803.

168. Broda, C. R.; Lee, J. Y.; Sirivisoot, S.; Schmidt, C. E.; Harrison, B. S., A chemically polymerized electrically conducting composite of polypyrrole nanoparticles and polyurethane for tissue engineering. J. Biomed. Mater. Res. A 2011, 98 A (4), 509-516.

169. Steven, E.; Lebedev, V.; Laukhina, E.; Rovira, C.; Laukhin, V.; Brooks, J. S.; Veciana, J., Silk/molecular conductor bilayer thin-films: properties and sensing functions. Mater. Horizons 2014, 1 (5), 522-528.

170. Jia, X.; Wang, C.; Zhao, C.; Ge, Y.; Wallace, G. G., Toward Biodegradable Mg-Air Bioelectric Batteries Composed of Silk Fibroin-Polypyrrole Film. Adv. Funct. Mater. 2016, 26 (9), 1454-1462.

171. Yan, J.; Wang, Q.; Wei, T.; Fan, Z., Recent Advances in Design and Fabrication of Electrochemical Supercapacitors with High Energy Densities. Adv. Energy Mater. 2014, 4 (4), 1300816.

172. Gaikwad, A. M.; Arias, A. C.; Steingart, D. A., Recent Progress on Printed Flexible Batteries: Mechanical Challenges, Printing Technologies, and Future Prospects. Energy Technol. 2015, 3 (4), 305-328.

173. Cai, X.; Zhang, C.; Zhang, S.; Fang, Y.; Zou, D., Application of carbon fibers to flexible, miniaturized wire/fiber-shaped energy conversion and storage devices. J. Mater. Chem. A 2017, 5 (6), 2444-2459.

174. Yu, D.; Qian, Q.; Wei, L.; Jiang, W.; Goh, K.; Wei, J.; Zhang, J.; Chen, Y., Emergence of fiber supercapacitors. Chem. Soc. Rev. 2015, 44 (3), 647-662.

175. Wang, W.; Tian, M.; Abdulagatov, A.; George, S. M.; Lee, Y.-C.; Yang, R., ThreeDimensional Ni/TiO2 Nanowire Network for High Areal Capacity Lithium Ion Microbattery Applications. Nano Lett. 2012, 12 (2), 655-660. 
176. Mao, L.; Meng, Q.; Ahmad, A.; Wei, Z., Mechanical Analyses and Structural Design Requirements for Flexible Energy Storage Devices. Adv. Energy Mater., 2017, 7 (23), 1700535. 177. Jin, B.; Gu, H.-B.; Kim, K.-W., Effect of different conductive additives on charge/discharge properties of LiCoPO4/Li batteries. J. Solid State Electrochem. 2008, 12 (2), 105-111.

178. Ha, D.-H.; Islam, M. A.; Robinson, R. D., Binder-Free and Carbon-Free Nanoparticle Batteries: A Method for Nanoparticle Electrodes without Polymeric Binders or Carbon Black. Nano Lett. 2012, 12 (10), 5122-5130.

179. Persson, N. E.; Chu, P.-H.; McBride, M.; Grover, M.; Reichmanis, E., Nucleation, Growth, and Alignment of Poly(3-hexylthiophene) Nanofibers for High-Performance OFETs. Acc. Chem. Res. 2017, 50 (4), 932-942.

180. Innis, P. C.; Masdarolomoor, F.; Kane-Maguire, L. A. P.; Forster, R. J.; Keyes, T. E.; Wallace, G. G., Chemical and Photoluminescence Properties of Purified Poly(2methoxyaniline-5-sulfonic acid) and Oligomer. J. Phys. Chem. B 2007, 111 (44), 12738-12747.

181. Cao, Y.; Smith, P.; Heeger, A. J., Counter-ion induced processibility of conducting polyaniline and of conducting polyblends of polyaniline in bulk polymers. Synth. Met. 1992, 48 (1), 91-97.

182. Cao, Y.; Smith, P.; Heeger, A. J., Counter-ion induced processibility of conducting polyaniline. Synth. Met. 1993, 57 (1), 3514-3519.

183. Mirabedini, A.; Foroughi, J.; Wallace, G. G., Developments in conducting polymer fibres: from established spinning methods toward advanced applications. $R S C A d v$. 2016, 6 (50), 44687-44716.

184. Mattes, B. R.; Wang, H. L.; Yang, D.; Zhua, Y. T.; Blumenthala, W. R.; Hundleya, M. F., Formation of conductive polyaniline fibers derived from highly concentrated emeraldine base solutions. Synth. Met. 1997, 84 (1), 45-49.

185. Wang, C. Y.; Mottaghitalab, V.; Too, C. O.; Spinks, G. M.; Wallace, G. G., Polyaniline and polyaniline-carbon nanotube composite fibres as battery materials in ionic liquid electrolyte. J. Power Sources 2007, 163 (2), 1105-1109.

186. Okuzaki, H.; Ishihara, M., Spinning and Characterization of Conducting Microfibers. Macromol. Rapid Commun. 2003, 24 (3), 261-264.

187. Li, L.; Peng, S.; Lee, J. K. Y.; Ji, D.; Srinivasan, M.; Ramakrishna, S., Electrospun hollow nanofibers for advanced secondary batteries. Nano Energy 2017, 39, 111-139.

188. Xue, J.; Xie, J.; Liu, W.; Xia, Y., Electrospun Nanofibers: New Concepts, Materials, and Applications. Acc. Chem. Res. 2017, 50 (8), 1976-1987.

189. Cárdenas, J. R.; França, M. G. O. d.; Vasconcelos, E. A. d.; Azevedo, W. M. d.; Silva, E. F. d., Growth of sub-micron fibres of pure polyaniline using the electrospinning technique. J. Phys. D 2007, 40 (4), 1068-1071.

190. Ju, Y.-W.; Park, J.-H.; Jung, H.-R.; Lee, W.-J., Electrochemical properties of polypyrrole/sulfonted SEBS composite nanofibers prepared by electrospinning. Electrochim. Acta 2007, 52 (14), 4841-4847.

191. Sousa, R. E.; Costa, C. M.; Lanceros-Méndez, S., Advances and Future Challenges in Printed Batteries. ChemSusChem 2015, 8 (21), 3539-3555.

192. Wallace, G. G.; Higgins, M. J.; Moulton, S. E.; Wang, C., Nanobionics: the impact of nanotechnology on implantable medical bionic devices. Nanoscale 2012, 4 (15), 4327-4347.

193. Li, D.; Lai, W.-Y.; Zhang, Y.-Z.; Huang, W., Printable Transparent Conductive Films for Flexible Electronics. Adv. Mater. 2018, 30 (10), 1704738.

194. Ambrosi, A.; Pumera, M., 3D-printing technologies for electrochemical applications. Chem. Soc. Rev. 2016, 45 (10), 2740-2755.

195. Jang, J.; Oh, J. H.; Stucky, G. D., Fabrication of Ultrafine Conducting Polymer and Graphite Nanoparticles. Angew. Chem. Int. Ed. 2002, 41 (21), 4016-4019. 
196. Katz, H. E.; Searson, P. C.; Poehler, T. O., Batteries and charge storage devices based on electronically conducting polymers. J. Mater. Res. 2010, 25 (8), 1561-1574.

197. Ngamna, O.; Morrin, A.; Killard, A. J.; Moulton, S. E.; Smyth, M. R.; Wallace, G. G., Inkjet Printable Polyaniline Nanoformulations. Langmuir 2007, 23 (16), 8569-8574.

198. Oh, S.-G.; Im, S.-S., Electroconductive polymer nanoparticles preparation and characterization of PANI and PEDOT nanoparticles. Curr. Appl. Phys. 2002, 2 (4), 273-277.

199. Holness, F. B.; Price, A. D., Direct ink writing of 3D conductive polyaniline structures and rheological modelling. Smart Mater. Struct. 2017, 27 (1), 015006.

200. Rivnay, J.; Inal, S.; Salleo, A.; Owens, R. M.; Berggren, M.; Malliaras, G. G., Organic electrochemical transistors. Nat. Rev. Mater. 2018, 3, 17086.

201. Crowley, K.; Morrin, A.; Hernandez, A.; O’Malley, E.; Whitten, P. G.; Wallace, G. G.; Smyth, M. R.; Killard, A. J., Fabrication of an ammonia gas sensor using inkjet-printed polyaniline nanoparticles. Talanta 2008, 77 (2), 710-717.

202. Fan, L.; Zhang, N.; Sun, K., Flexible patterned micro-electrochemical capacitors based on PEDOT. Chem. Commun. 2014, 50 (51), 6789-6792.

203. Xu, Y.; Schwab, M. G.; Strudwick, A. J.; Hennig, I.; Feng, X.; Wu, Z.; Müllen, K., Screen-Printable Thin Film Supercapacitor Device Utilizing Graphene/Polyaniline Inks. Adv. Energy Mater. 2013, 3 (8), 1035-1040.

204. Hilder, M.; Winther-Jensen, B.; Clark, N. B., Paper-based, printed zinc-air battery. J. Power Sources 2009, 194 (2), 1135-1141.

205. Tehrani, Z.; Korochkina, T.; Govindarajan, S.; Thomas, D. J.; O’Mahony, J.; Kettle, J.; Claypole, T. C.; Gethin, D. T., Ultra-thin flexible screen printed rechargeable polymer battery for wearable electronic applications. Organ. Electron. 2015, 26, 386-394.

\section{Author introduction}

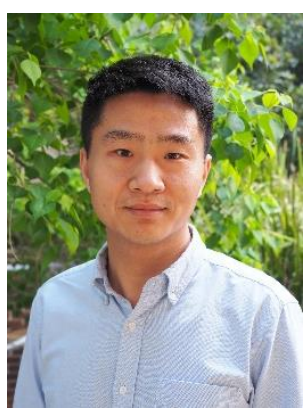

Xiaoteng Jia received both of double B.Sc. degrees (2010) in Chemistry and Biotechnology and M.Sc. degree (2013) in Polymer Chemistry and Physics at Jilin University, and PhD degree at ARC Centre of Excellence for Electromaterials Science (ACES), the University of Wollongong in 2017. Dr. Jia is currently a postdoctoral scholar at University of California, Irvine. His research interests include the preparation of electrical and ionic conductive proteinbased materials for bioelectronics and bio-batteries. 


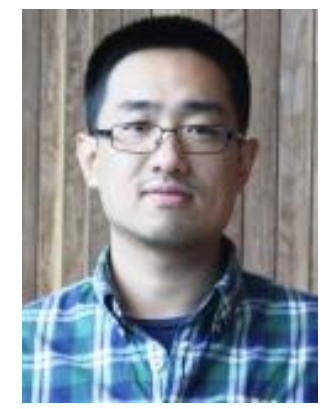

Yu Ge received his B.S. degree and M.S. degree from the School of Chemistry and Chemical Engineering at Shanghai Jiaotong University in 2009 and 2012. He is currently a PhD candidate under supervision of Prof. Gordon Wallace and Dr. Caiyun Wang at the University of Wollongong. His research interests focus on graphene and its inorganic analogues-based electrodes for energy storage devices.

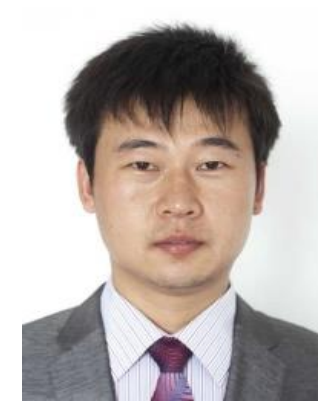

Liang Shao received his PhD degree at Lanzhou University in 2011. Dr. Shao is currently an associate professor of Shaanxi Key Laboratory of Chemical Additives for Industry, Shaanxi University of Science and Technology. His research interests include morphology control of conducting polymer and applications in energy storage systems and sensing devices.

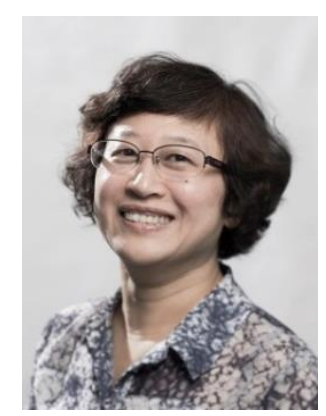

Caiyun Wang completed her BSc at Shandong Normal University, MSc in Physical Organic Chemistry at Nankai University, and $\mathrm{PhD}$ in Materials Engineering at the University of Wollongong. Dr. Wang is currently a Senior Research Fellow at the Intelligent Polymer Research Institute (IPRI), ARC Centre of Excellence for Electromaterials Science (ACES), 
University of Wollongong. Her research interests include conducting polymers and twodimensional materials for energy storage applications; nanostructured catalysts for the electrochemical reduction of $\mathrm{CO}_{2}$.

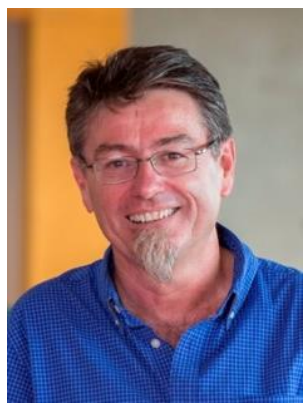

Professor Gordon Wallace is currently the Executive Research Director at the ARC Centre of Excellence for Electromaterials Science, Director of the Australian National Fabrication Facility (Materials Node), and Director of the Intelligent Polymer Research Institute. He previously held an ARC Federation Fellowship and currently holds an ARC Laureate Fellowship. Professor Wallace's research interests include organic conductors, nanomaterials and electrochemical probe methods of analysis, and the use of these in the development of Intelligent Polymer Systems. A current focus involves the use of these tools and materials in developing bio-communications from the molecular to skeletal domains to improve human performance via medical Bionics. 
Conducting polymers with structural diversity in molecular design has enabled the modulation of their intrinsic properties towards sustainable and versatile batteries.

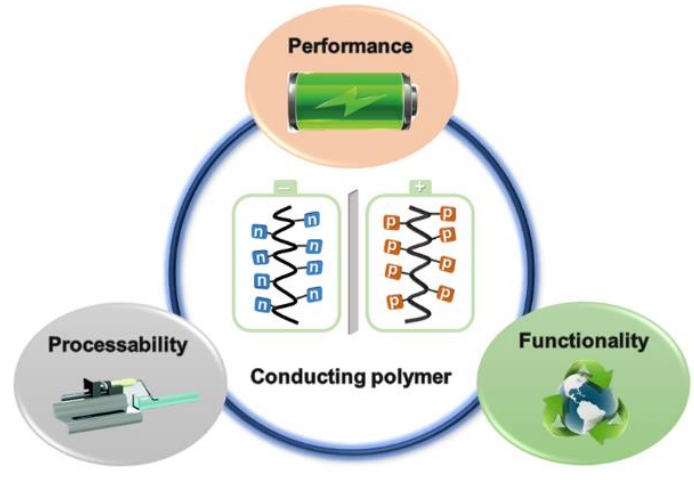

Graphical abstracts 